\title{
Soft Tissue Sarcoma Follow-up Imaging: Strategies to Distinguish Post-treatment Changes from Recurrence
}

\author{
Iris-M. Noebauer-Huhmann, MD, $\mathrm{PhD}^{1}$ Snehansh R. Chaudhary, $\mathrm{MD}^{2}$ \\ Olympia Papakonstantinou, MD, $\mathrm{PhD}^{3}$ Joannis Panotopoulos, MD, $\mathrm{PhD}^{4}$ Marc-André Weber, MD, MSc ${ }^{5}$ \\ Radhesh K. Lalam, MBBS, MRCS, FRCR ${ }^{6}$ Omar M. Albtoush, MD ${ }^{7}$ Barbara J. Fueger, MD ${ }^{8}$ \\ Pavol Szomolanyi, PhD ${ }^{9}$ Thomas Grieser, MD ${ }^{10}$ Johan L. Bloem, MD, PhD ${ }^{11}$
}

${ }^{1}$ Division of Neuroradiology and Musculoskeletal Radiology, Department of Biomedical Imaging and Image-guided Therapy, Medical University of Vienna, Vienna, Austria

2 Department of Clinical Radiology, Aintree University Hospitals NHS Foundation Trust, Liverpool, United Kingdom

${ }^{3}$ 2nd Department of Radiology, National University of Athens, "Attikon" Hospital, Athens, Greece

${ }^{4}$ Department of Orthopedics and Trauma-Surgery, Medical University of Vienna, Vienna, Austria

${ }^{5}$ Institute of Diagnostic and Interventional Radiology, Pediatric Radiology and Neuroradiology, University Medical Center Rostock, Rostock, Germany

${ }^{6}$ Department of Radiology, Robert Jones and Agnes Hunt

Orthopaedic Hospital, Oswestry, United Kingdom

${ }^{7}$ Department of Radiology, University of Jordan, and Department of Radiology, King Hussein Cancer Center, Amman, Jordan

${ }^{8}$ Department of Biomedical Imaging and Image Guided Therapy, Medical University of Vienna, Vienna, Austria

${ }^{9}$ High Field MR Center, Department of Biomedical Imaging and Image Guided Therapy, Medical University of Vienna, Vienna, Austria

10 Department of Diagnostic and Interventional Radiology and Neuroradiology, University Hospital Augsburg, Augsburg, Germany

11 Department of radiology, Leiden University Medical Center, Leiden, The Netherlands
Address for correspondence Iris-M. Noebauer-Huhmann, MD, PhD, Division of Neuroradiology and Musculoskeletal Radiology, Department of Biomedical Imaging and Image-guided Therapy, Medical University of Vienna, Vienna, Austria (e-mail: iris.noebauer@meduniwien.ac.at).

Semin Musculoskelet Radiol 2020;24:627-644.

\begin{abstract}
Keywords

- sarcoma

- recurrence

- aftercare

- magnetic resonance imaging

- postoperative complications

Soft tissue sarcomas encompass multiple entities with differing recurrence rates and followup intervals. The detection of recurrences and their differentiation from post-therapeutic changes is therefore complex, with a central role for the clinical radiologist. This article describes approved recommendations. Prerequisite is a precise knowledge of the current clinical management and surgical techniques. We review recurrence rates and treatment modalities. An adequate imaging technique is paramount, and comparison with previous imaging is highly recommended. We describe time-dependent therapy-related complications on magnetic resonance imaging compared with the spectrum of regular posttherapeutic changes. Early complications such as seromas, hematomas, and infections, late complications such as edema and fibrosis, and inflammatory pseudotumors are elucidated. The appearance of recurrences and radiation-associated sarcomas is contrasted with these changes. This systematic approach in follow-up imaging of soft tissue sarcoma patients will facilitate the differentiation of post-therapeutic changes from recurrences.
\end{abstract}

Issue Theme Bone and Soft Tissue Tumors: Part 2; Guest Editors, Radhesh Lalam, MBBS, MRCS, FRCR and MarcAndré Weber, MD, MSc (c) 2020. Thieme. All rights reserved. Thieme Medical Publishers, Inc., 333 Seventh Avenue, 18th Floor, New York, NY 10001, USA
DOI https://doi.org/ $10.1055 / \mathrm{s}-0040-1721464$. ISSN $1089-7860$. 


\section{Recurrence Epidemiology}

The diagnosis and therapy of patients with soft tissue tumors has improved in recent decades, with a much higher longterm survival rate, requiring an extended follow-up. Consensual interdisciplinary tumor board decisions in dedicated centers help adherence to optimized and standardized procedures for the individual patient. ${ }^{1-6}$

The local recurrence (LR) rates of soft tissue sarcomas reported in the literature vary considerably, with $\sim 8.5 \%$ of patients after 2 years, ${ }^{7} 17$ to $26 \%$ after 5 years, and 20 to $32 \%$ after 10 years. ${ }^{8,9}$ Well-differentiated liposarcoma was associated with late ( $>5$ years) local recurrences. ${ }^{10}$ Recurrences are more common in truncal sarcomas ${ }^{7}$ with almost $40 \%$ of cases after 5 years, compared with $\sim 4$ to $20 \%$ in extremity sarcomas. ${ }^{9}$ In general, localizations in the deep retroperitoneal and head and neck are associated with higher recurrence rates. ${ }^{8,11}$ In extremity sarcomas, radiotherapy further decreases local recurrence. ${ }^{12}$ With limb-preserving resection and postoperative radiation, rates of $9 \%$ after 5 years and $12 \%$ after 10 years ${ }^{3,13}$ can be achieved. LR is observed more often on the upper extremity than on the lower extremity. $^{14}$

The influence of positive resection margins on LR rate is under debate. An initial unplanned positive resection margin was shown to result in higher LR rates even after a wide reresection and adjuvant surgical therapy ${ }^{15}$ and increased the likelihood of earlier recurrence ${ }^{16}$ in some studies. Other studies failed to show the same results ${ }^{17}$ even in stage 3 sarcomas. $^{18}$ Microscopically positive resection margins (termed R1, in contrast to R0 margins, which are defined as microscopically negative) as such resulted in up to a 3 to 5.9 times increased risk of LR. $7,8,13,17,19-21$ Only in retroperitoneal sarcomas and primary fibrosarcoma was the local recurrence-free survival not altered by positive resection margins. ${ }^{22}$ Similarly, if a patient already has an LR, their future prognosis depends to a large extent on whether the resection margins during reoperation are negative, up to $2 \mathrm{~mm}$ or $>2 \mathrm{~cm} \cdot{ }^{13,23,24}$ In general, an unintentional $\mathrm{R} 1$ resection seems to be more common in myxofibrosarcomas and undifferentiated pleomorphic sarcomas, ${ }^{12,25}$ whereas $\mathrm{R} 0$ resection is more common in liposarcomas (apart from special difficulties with retroperitoneal liposarcomas) or generally low-grade sarcomas. ${ }^{24}$

Various studies indicate that patients benefit from a primary resection in a dedicated sarcoma center; adherence to approved guidelines has especially proved to be a crucial factor. ${ }^{26-29}$ Overall, intermediate and especially high histologic tumor grades as well as large tumors (especially $>10 \mathrm{~cm}$ ) also show higher LR rates. ${ }^{7-10,20,30}$ Additional unfavorable factors are a patient aged $>64$ years and certain tumor entities, such as undifferentiated pleomorphic sarcoma, myxofibrosarcoma, malignant peripheral nerve sheath tumor, angiosarcoma, and epithelioid sarcoma, $4,7,8,31,32$ as well as highly/dedifferentiated liposarcoma in the retroperitoneum. ${ }^{33,34}$ Overall survival in some studies largely depended on the occurrence of distant sarcoma metastases, whereas LRs mainly affected local tumor control. ${ }^{21}$ However, other studies also found that LRs had an impact on overall survival. ${ }^{13,31,35,36}$
Unfortunately, sarcoma recurrences tend to be deeper seated and higher graded compared with the initial tumor. ${ }^{37,38}$

\section{Overview of Therapeutic Options in Sarcoma}

For a radiologist, an understanding of the expected and unexpected changes following the different treatment options (surgery, in most cases including wide resection; radiotherapy; and chemotherapy) is crucial in interpreting follow-up studies.

\section{Reconstructive Surgery}

Myocutaneous flaps can serve to cover defects in extended resections. ${ }^{39}$ Pedicled flaps allow for a preserved neurovascular supply. ${ }^{40-42}$ Soft tissue sarcomas occur particularly frequently in the lower extremity. Patients with extensive tumors or in whom a prior incomplete surgery necessitate re-resection frequently require soft tissue reconstruction with flaps. Implants in particular need adequate coverage by viable muscular tissue. In the proximal thigh area, the most commonly used muscles for myocutaneous flaps are gluteals, tensor fasciae latae, biceps femoris, rectus femoris, and vertical rectus abdominis flap in the hip area. In the distal thigh, vastus lateralis and gracilis muscle are also used. ${ }^{40}$

Around the knee, the medial or lateral gastrocnemius is often pivoted, and in the case of large defects it may be combined with displacement of the soleus muscle. In areas with high mechanical loads (e.g., the sole of the foot), defect coverage with a well-vascularized neurofasciocutaneous flap such as the sural flap may be indicated. ${ }^{42}$

For extensive defect coverage or with limited local vascular supply, free flaps can be transplanted, whose vascular supply is reanastomosed. The rectus abdominis or latissimus dorsi muscle is mostly used for this purpose. ${ }^{40}$ The surgical outcome has improved with the use of flaps. ${ }^{43}$

\section{Radiotherapy}

In addition to the wide resection (with the aim of limb salvage), highly malignant sarcomas usually undergo adjuvant irradiation. For certain indications, neoadjuvant radiation is performed. The advantages and disadvantages due to the therapy sequence are further described in the section on imaging findings. The interval between surgery and radiation is currently under debate; it is usually 4 to 6 weeks. ${ }^{44-48}$

Low-grade sarcomas are typically irradiated if the safety distance of the resection is $<1 \mathrm{~cm}$ or marginal and no subsequent resection is planned. ${ }^{49,50}$ In principle, choice of the chronological order of surgery and radiation has largely no influence on the local tumor control, metastasis rate, or overall survival as a result of the disease (except in the case of tumors that would have been difficult to resect anatomically or are primarily unresectable); in most cases, radiation is given postoperatively (adjuvant). $45,48,51$

Preoperative radiotherapy (RT) has some advantages. A lower dose (50 Gy) can be given compared with postoperative RT, and also the planning of the RT is easier. Two targets have to be defined: the gross tumor volume, as seen on imaging, and the clinical target volume including potential 
microscopic disease, usually an additional 2 to $5 \mathrm{~cm}$. Insertion of metalwork also causes problems with postoperative RT. As alluded to earlier, preoperative radiation can make inoperable tumors operable. ${ }^{52-54}$

However, wound complications are more likely with preoperative RT, with an odds ratio of 2.9 compared with postoperative radiation. ${ }^{55}$ In postoperative radiation, target volumes are significantly larger because they include the entire surgical area. Due to the altered anatomy, the definition of the irradiation target volumes is more difficult. With individual doses of 60 to $66 \mathrm{~Gy}$ in the tumor bed and $50 \mathrm{~Gy}$ in the operative area, higher radiation doses are used (depending on the location of the tumor bed and the resection margins). In definitive RT of inoperable patients, radiation doses should be increased locally to $>60 \mathrm{~Gy}$ whenever possible to achieve better local control. ${ }^{56}$

\section{Chemotherapy}

Chemotherapy is not part of the routine treatment of soft tissue sarcomas. It is a preferred option for patients with metastatic disease. If used in LR, it should be combined with radical re-resection, if possible. However, the ability of additional neoadjuvant or adjuvant chemotherapy (usually with ifosfamide and doxorubicin) in reducing the LR rate, rate of metastases, and recurrence-free survival or overall survival $^{57,58}$ is not fully clear. Presumably, patients with large grade 3 limb sarcomas in particular benefit from chemotherapy. ${ }^{59}$

\section{Imaging Strategies for Follow-up}

Currently, no evidence-based consensus exists about how regular follow-up imaging influences the outcome of sarcoma patients. Studies have shown that the survival rate of high-risk patients with soft tissue sarcomas can be improved by regular local imaging follow-ups. ${ }^{60}$ LRs of extremity soft tissue sarcomas may already be clinically noticeable due to a palpable lump or pain. ${ }^{61}$ However, in several studies, magnetic resonance imaging (MRI) was superior in detecting LR compared with clinical examination ${ }^{62}$ even in extremity sarcoma recurrences. ${ }^{63}$ Detection of $>50 \%$ clinically inapparent nonpelvic LR by MRI was reported. ${ }^{64}$

An exact knowledge of the resection margins is important, and the detection of clinically inapparent high-grade sarcoma LR can be further improved by including a dynamic contrast-enhanced (DCE) sequence. ${ }^{65}$ Moreover, physical examination in terms of tactile findings can be of limited value when post-therapeutic changes are present or in deeper structures. Individual authors advise limiting imaging follow-up to cases that are difficult to evaluate clinically or high-risk patients. ${ }^{61,66}$

It is useful to bear in mind that the risk of soft tissue sarcoma patients for LR decreases after the first few years. ${ }^{67-69}$ Current guidelines, such as those published by the European Society of Musculoskeletal Radiology (ESSR), recommend regular routine checks with local imaging and chest computed tomography (CT) up to 10 years after the first treatment. Because high-grade soft tissue sarcomas tend to reoccur earlier than intermediateor low-grade sarcomas (11.2 versus 36.6 and 35.2 months,
Table 1 Examples of follow-up intervals after soft tissue sarcoma

\begin{tabular}{|l|l|}
\hline \multicolumn{2}{|l|}{$\begin{array}{l}\text { Clinical examination, locoregional MRI, and chest CT scan } \\
\text { (no contrast agent) }\end{array}$} \\
\hline Year after first treatment & Follow-up interval \\
\hline $1-3$ & $\begin{array}{l}\text { Grading dependent } \\
\text { every 3-4 mo }\end{array}$ \\
\hline $3-5$ & Every 6 mo \\
\hline$>5$, up to 10 & Annually \\
\hline
\end{tabular}

Abbreviations: CT, computed tomography; MRI, magnetic resonance imaging.

respectively), ${ }^{64}$ the recommended examination intervals depend on the histologic degree of the sarcoma but also on the site of the primary tumor (extremity/superficial trunk, head/neck, or retroperitoneal/abdominal) and the period since primary therapy $^{70-73}$ (- Table 1) ${ }^{72}$

Depending on the entity, further investigation modalities may be indicated. ${ }^{74}$ Also, depending on the entity, adjusting the time intervals and the overall surveillance period may be needed. ${ }^{75}$ Well-differentiated liposarcomas and myxoid liposarcoma were associated with late LR as long as 15 years from diagnosis. ${ }^{76}$ Nomograms may help in the future to further refine surveillance protocols.

MRI with contrast is currently the gold standard for local follow-up scans. High sensitivities $\sim 90 \%$ and $100 \%$, and specificities $\sim 97 \%$ were reported. ${ }^{77,78}$ In easily accessible regions, a follow-up inspection can alternatively be performed with sufficient expertise using ultrasound to exclude a mass. ${ }^{79,80}$

Fluorodeoxyglucose (FDG) positron emission tomography (PET)/CT imaging was shown to be helpful in assessing possible LR. It has a higher sensitivity and specificity of $100 \%$ and $95.6 \%$, respectively, in comparison with $97.2 \%$ and $63.5 \%$, respectively, for $\mathrm{CT}$ imaging. ${ }^{81}$ However, various benign processes such as infectious diseases and postsurgical and post-RT states as well as the use of granulocyte colonystimulating factors can lead to false-positive results. ${ }^{82}$ According to a study, PET/CT is comparable in sensitivity (95\% PET/CT versus $90 \% \mathrm{MRI}$ ) and specificity (95.5\% versus $97.7 \%$ in the detection of recurrence and therefore may act as an adjunct to MRI findings. ${ }^{77}$ It may be justified in regions such as the retroperitoneum or in the ear, nose, and throat area if the initial tumor was PET avid, ${ }^{70,83}$ simultaneously offering the advantage of showing distant metastases.

For myxoid liposarcoma, for which PET/CT has a high false-negative rate in detecting $\mathrm{LR}^{70}$ follow-up with wholebody MRI was advocated. ${ }^{84}$ In PET-avid soft tissue sarcomas, PET/MR is promising in detecting LR when compared with MRI alone. ${ }^{85}$ However, PET/MR is only available at a few sites.

\section{MRI Technique}

To fully visualize the surgical site, the edges of the postoperative scar should be marked with glued cutaneous markers. ${ }^{86}$ The field of view should be large enough to include all adjacent post-therapeutic signal alterations, and the site should be evaluable in all three dimensions. 
The sequence listing should contain a fluid-sensitive sequence and a T1-weighted sequence in the long axis as well as a fluid-sensitive, fat-suppressed sequence in the short axis. ${ }^{87}$ A T2-weighted sequence without fat saturation can offer additional morphological information, especially if it shows hypointense areas, suggesting fibrosis, calcifications (together with projection radiographs), or substance deposits. ${ }^{88}$ The application of a contrast agent is recommended unless clinical or imaging circumstances dictate otherwise. ${ }^{87}$ The postcontrast sequences should include an axial fat-saturated sequence. The use of one T1-weighted Dixon sequence allows for postprocessing with reconstruction of in-phase and out-phase, water-only, and fat-only images, so the number of sequences can be reduced (precontrast, the fat content can additionally be assessed); T2weighted or proton-density Dixon are also possible. However, motion and breathing artifacts are increased. ${ }^{89}$ Subtraction imaging can increase lesion conspicuity. A dynamic contrast sequence and diffusion are desirable. In special cases, a hemosiderin-sensitive sequence can be added. We generally recommend a protocol as described in the ESSR guidelines. ${ }^{72,78,90}$

Radiomics MR analysis is promising in better differentiating LR from post-therapeutic alterations in the future. ${ }^{91}$ With metallic implants or foreign bodies, a lower field strength magnet (e.g., $1.5 \mathrm{~T}$ ) and metal artifact reduction sequences are adapted. In the case of significant metal artifacts, expected or otherwise, the implementation of an ultrasound or a PET/CT should be considered alternatively.

\section{Before Starting the Report}

Precondition for diagnosis is a precise knowledge of the patient's medical history and clinical examination. It should include these items:

- Knowledge about the initial diagnosis of tumor entity, histologic tumor grade, localization (deep/superficial, as well as the body section), and the size of the tumor. This includes availability of all pre- and post-therapeutic scans (including the first postoperative imaging as an important baseline exam $)^{28}$ to know the exact location, extent, and morphology of the original tumor because the recurrent tumor is often similar to that of the primary tumor. ${ }^{86}$

- Knowledge of previous therapies (including the resection margins) to be able to classify post-therapeutic changes.

- Knowledge of the current clinical presentation if possible. The physician should carry out a short inspection and palpation of the local site to look for radiation dermatitis, subcutaneous fibrosis, or ulceration and describe the extent of the palpable tumor and reconstruction site, ${ }^{92}$ if possible.

\section{Post-therapeutic Changes}

\section{Regular Post-therapeutic Soft Tissue Changes}

These changes include edema, inflammatory tissue reaction, granulation tissue, fibrosis, and scars. Postsurgery, immediate diffuse edema is normal, as well as a subsequent diffuse edema-like pattern by granulation tissue (described in more detail in the article by Bloem et al in this issue). Following radiation therapy, increase and longer persistence of those changes is also normal. ${ }^{26,93,94}$
The initially very variable edema-like signal increases over time with a peak $\sim 12$ to 18 months after irradiation with photons and $\sim 6$ months after neutron irradiation. Normalization is less frequent and occurs later after neutrons compared with protons. ${ }^{26,93,95}$

In the subcutaneous tissue, the collagenous septations typically lead to lattice-like fluid-equivalent signal change, whereas the changes in the muscles (which are observed in $80 \%$ of patients after surgery with additional radiation) are more diffuse. The tissue architecture is naturally preserved and the contrast uptake is very low, ${ }^{26,96}$ which is helpful in the differentiation from recurrence. If the tissue is diffusely edematous, but the architecture of the muscles is preserved with muscle pennation visible on all sides on T1-weighted sequences ("texture" or "feathering sign"), tumor recurrence is rather unlikely ${ }^{26,96,97}$ (-Fig. 1). The changes in the intermuscular septa persist significantly longer than in the muscle or adipose tissue. It is important to keep in mind that the thickness of the intermuscular septa and adipose tissue can increase over time ${ }^{93}$ also without recurrence.

Postinflammatory tissue or fibrosis after surgery can be bulky, and the presence of nodular enhancement neither predicts nor excludes microscopic residual tumor. ${ }^{16}$ As opposed to recurrence, post-therapeutic tissue almost never shows arterial enhancement on the DCE sequence (specificity of $97 \%$ for recurrence) ${ }^{78} \mathrm{~A}$ visual impression of the clinical severity of cutaneous changes such as the presence of cellulitis or ulceration can be helpful in the image assessment of deeper changes.

Muscular flap plastic surgery also initially shows an edema-like signal (-Fig. 2) that normalizes in about a third of the patients within 2 years. In $\sim 75 \%$ of the patients, there is an initial contrast enhancement of the flap that is no longer detectable in about a third of the patients after 1.5 years. ${ }^{39}$ For development of atrophy, see the article by Bloem et al. ${ }^{95}$

In the final state, the post-therapeutic scar tissue is ideally hypointense on all sequences. ${ }^{89,98}$ As a rule of thumb, the size and complexity of the entire postoperative scar tissue correlate with the size of the resected tissue and the entire surgical field..$^{94}$ On T2-weighted sequence, if only hypointense tissue is found, recurrence can be excluded in $99 \%$ of the cases. ${ }^{96}$ The irradiated bone also shows MR signal alterations, in particular after additional chemotherapy and mostly focal in various patterns and with subsequent dose and location-dependent fatty marrow conversion, ${ }^{99-102}$ as described in more detail by Bloem et al. ${ }^{95}$

\section{Occurrence and Imaging of Complications}

Local complications must be distinguished from these regular post-therapeutic changes. In addition to defined postoperative seromas and hemorrhages, these also include posttherapeutic infections, tissue necrosis, and failure of flap reconstructions. The risk of postoperative local complications increases with additional radiation. ${ }^{26,96,103}$

Acute wound healing disorders such as wound dehiscences, seromas, or infections occur more frequently with neoadjuvant radiation (34-35\%) than with adjuvant radiation (16-17\%). ${ }^{52,54}$ They can also be observed increasingly in patients with diabetes, 

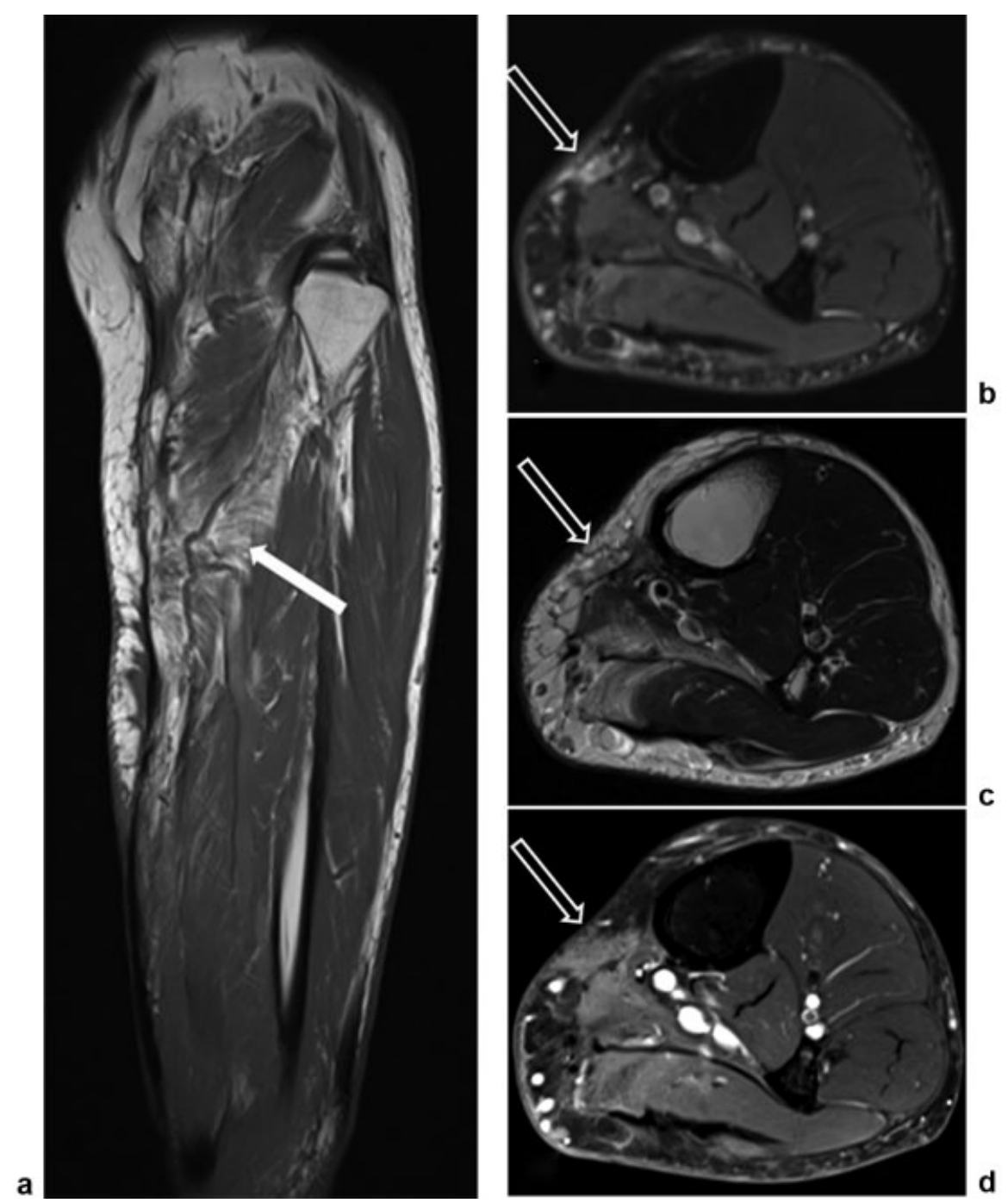

Fig. 1 Post-therapeutic changes and T1-weighted "texture" or "feathering sign" in a 74-year-old male patient, 12 years after myxofibrosarcoma of the lower leg (initial intralesional resection at another institution; revision and radiation therapy; recurrence after 9 years with isolated limb perfusion and subsequent wide resection, partial resection of the gastrocnemius and soleus, and soleus muscle flap). (a) In the follow-up magnetic resonance imaging 2 years later, the coronal T1-weighted sequence shows the typical texture or feathering sign of fatty muscular atrophy (arrow). In the (b) axial proton-density fat-saturated (FS), (c) T2-weighted, and (d) T1-weighted FS postgadolinium sequences, minor edema and enhancement in the operative site, including the remnants of gastrocnemius and soleus muscle, is also depicted (open arrows).

large tumors (different limit values of 5 or $10 \mathrm{~cm}$ are described in the literature), surgeries requiring vascular pedicle flaps, and split-thickness skin coverage. ${ }^{54,104}$

However, patients who received postoperative radiation with large target volumes are more likely to experience late complications than patients with neoadjuvant radiation. These include edema (23.2\% in postoperative versus $15.1 \%$ in neoadjuvant radiation), fibrosis ( $48.2 \%$ versus $31.5 \%$ ), and joint stiffness in cases where the joint was irradiated $(23.2 \%$ versus $17.8 \%){ }^{47}$ This applies particularly to patients with postoperative wound complications, with tumors in the groin or on the thigh, and with radiation doses $>60 \mathrm{~Gy} .{ }^{54}$

\section{Seroma}

Characteristically, frequently occurring postoperative seromas demonstrate a smooth lining, with homogeneous fluid intensity contents ( $\mathbf{- F i g . 2}$ ). However, they appear lighter on T1-weighted sequences when protein is abundant. Seromas can be inhomogeneous when debris is included and rarely have fluid levels. The serum content typically does not show contrast enhancement. ${ }^{26,105}$

Seromas are usually surrounded by a mostly thin pseudocapsule that takes up moderate and late contrast enhancement. ${ }^{105}$ Seromas with small nodular areas ( - Figs. 3 and $\mathbf{4}$ ), which are often relatively hypointense, may mimic organized hematomas. LRs within seromas are rare. ${ }^{106}$ Most seromas regress within 3 to 18 months. ${ }^{26,94}$

\section{Hematoma}

Recurrence exclusion can be more difficult if there is a postoperative hematoma ( $\mathbf{- F i g . 5}$ ). The contained hemosiderin can be detected more sensitively by means of gradient echo sequences due to its paramagnetic effect ("blooming"). In general, however, hematomas appear inhomogeneous due to different blood products. If you give contrast agent (KM) and then examine T1-weighted subtraction images (postcontrast agent minus 

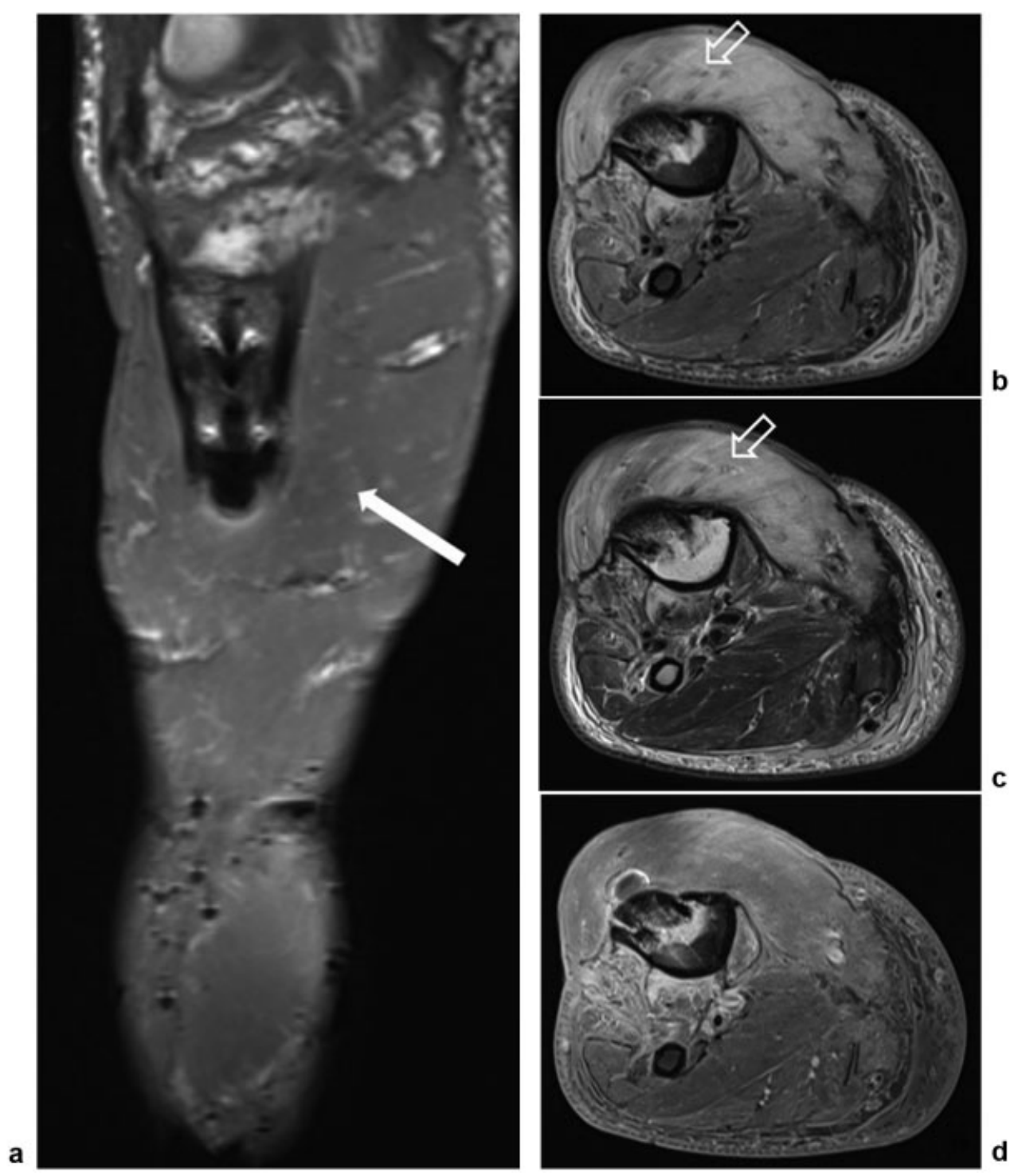

Fig. 2 Post-therapeutic changes and "texture" or "feathering sign" in a 64-year-old male patient with initial unintended intralesional resection of myxofibrosarcoma ("whoops") at an outside institution. In-house radiation therapy and revision with wide resection and osteoligamentous allograft (arrow), wound healing disorder with debridement, cutaneous flap and partial soleus flap, and split-thickness skin graft. Magnetic resonance imaging 3 months later. (a) Coronal T1-weighted sequence, (b) axial proton-density fat-saturated (FS), (c) T2-weighted, and (d) T1weighted FS postgadolinium images show extensive edema-like signal of the flap. The feathering sign is best depicted in sequences with high contrast between fluid and muscle (open arrows). The adjacent tissue shows diffuse inflammatory changes and muscle atrophy.

precontrast), misinterpretation of hyperintense blood products as contrast enhancement can be avoided. However, hematomas can also take up small amounts of contrast due to organizational processes, and their appearance can change during hematoma organization (-Fig. 2e-i). Organized hematomas can liquify. ${ }^{107}$

According to a study, the diffusing capacity in hematomas is significantly higher than in soft tissue sarcoma relapses or pseudotumors. ${ }^{78}$ The so-called chronic expanding hematoma is a particular problem. It appears inhomogeneous (due to a mixture of different blood products, granulation tissue with injecting capillaries, inflammatory tissue, necrotic debris, and fibrin ${ }^{108}$ ) and usually has a pseudocapsule (made of fibrin, hemosiderin deposits, and macrophages). ${ }^{107}$ The diffusionweighted sequence can again be helpful because the apparent diffusion coefficient (ADC) is also significantly higher in chronic expanding hematomas than in soft tissue sarcoma tissue. ${ }^{109}$
The chronic expanding hematoma grows slowly, presumably due to an irritation of the blood products that repeatedly leads to capillary injuries and new bleeding. ${ }^{110}$ It can therefore have nodular contrast-enhancing parts. But recurrences can also bleed slowly, and therefore a reliable exclusion of recurrence may only be possible through a biopsy. ${ }^{107}$

\section{Infection/Abscess}

Infections after resection of musculoskeletal tumors occur in $\sim 12.2 \%$ of patients with malignant tumors ( - Fig. 6 ) and only in $\sim 0.32 \%$ with benign tumors. The likelihood increases with a long duration of surgery, greater blood loss, preoperative chemotherapy (the effects of radiation have not been investigated), and after implants. Three to four of these risk factors increase the likelihood of developing an infection to $38.5 \% .{ }^{111}$ 


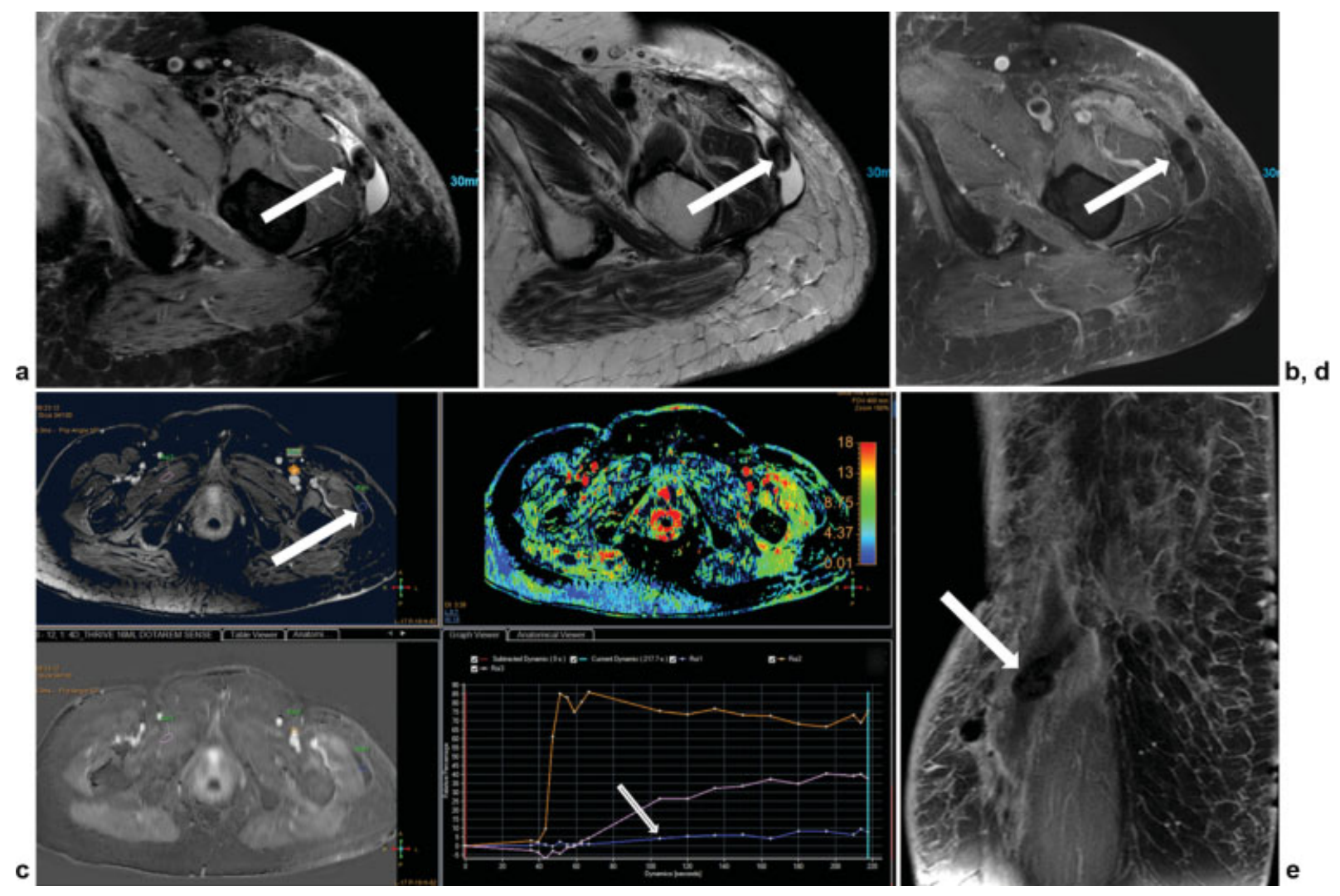

Fig. 3 Seroma with small dark pseudotumor. Magnetic resonance imaging of the left thigh 1 year after resection of an spindle cell sarcoma in a 68-year-old female patient. (a) Axial proton-density, (b) T2-weighted, as well as (c) dynamic contrast-enhanced (DCE) and (d) axial and (e) coronal T1-weighted fatsaturated postgadolinium images show a small persisting nonenhancing nodule (arrows) within a small postoperative seroma (small arrow points at curve in DCE). The fibrotic capsule of the retention still enhances, and there are minor adjacent postoperative muscle changes.

The tissue (e.g., muscle flaps) can be destroyed by infection spread or become necrotic due to increased metabolism. ${ }^{103}$ The MR morphology of soft tissue abscesses after tumor resection generally corresponds to that of abscesses of another cause, with circumscribed fluid retention, hypo or intermediate intense signal on T1-weighted sequence, hyperintense signal on $\mathrm{T} 2$-weighted sequence without central enhancement, with a hypointense, thick, irregular, enhancing marginal border. ${ }^{112,113}$

However, the differential diagnosis compared with seromas is difficult due to the already existing post-therapeutic diffuse changes. Individual studies report at least initially restricted diffusion in the abscess compared with seromas. ${ }^{114}$ It is important to know the clinical condition of the patient and their laboratory values. A precise knowledge of the irradiated field helps differentiate it from postradiation noninfectious changes. ${ }^{115}$

\section{Inflammatory Pseudotumor, Hypertrophic Scar, Neuroma, and Nerve Swelling}

So-called inflammatory pseudotumors have also been described after radiation with a prevalence between $5 \%$ and $12.5 \%$ and after radiation doses of $\sim 55 \mathrm{~Gy}^{95,116}$ (- Fig. 7). These pseudotumors can occur at variable time intervals after the start of therapy, in one study after 38 months on average, with isolated cases between 1 and 12 years after resection and radiation. ${ }^{116}$ They are described as oval lesions that are signal rich on fluid-sensitive sequences and less signal rich on T1-weighted sequences compared with the muscles. These are often confined and not very bulky. The contrast uptake is clearly heterogeneous, but in contrast to tumor recurrences it is delayed in dynamic sequences. The contrast enhancement takes place only 3 to 9 minutes after administration of contrast, compared with recurrences that typically show early contrast enhancement after 1 to 2 minutes. ${ }^{90,96,116}$ Histologically, they should correspond to vascular ectasia and fibrosis. ${ }^{116}$

Hypertrophic scar tissue (-Fig. 8) presents as a postoperative growing palpable lump. Histologically, there is increased cellularity, enlarged arterioles and capillaries, excessive collagen, inflammatory changes, and bleeding. In individual cases, $\mathrm{T} 2$-weighted images can therefore also be hyperintense in some cases. ${ }^{117}$

Both tumor recurrence and fibrosis can lead to nerve compression with denervation edema and fatty muscle atrophy (- Fig. 9). ${ }^{26}$ After nerve reconstruction with a graft, for example with an autologous sural nerve interposition, a neurologic deficit often remains. Even with a very good clinical result, local changes (e.g., small neuromas) may be visible ( - Fig. $3^{118,119}$ ) and should not be confused with nodular recurrence.

A very rare postamputation finding is sciatic nerve swelling proximal to the surgical stump (-Fig. 10). The pathomechanism is still unclear. It has been attributed to 


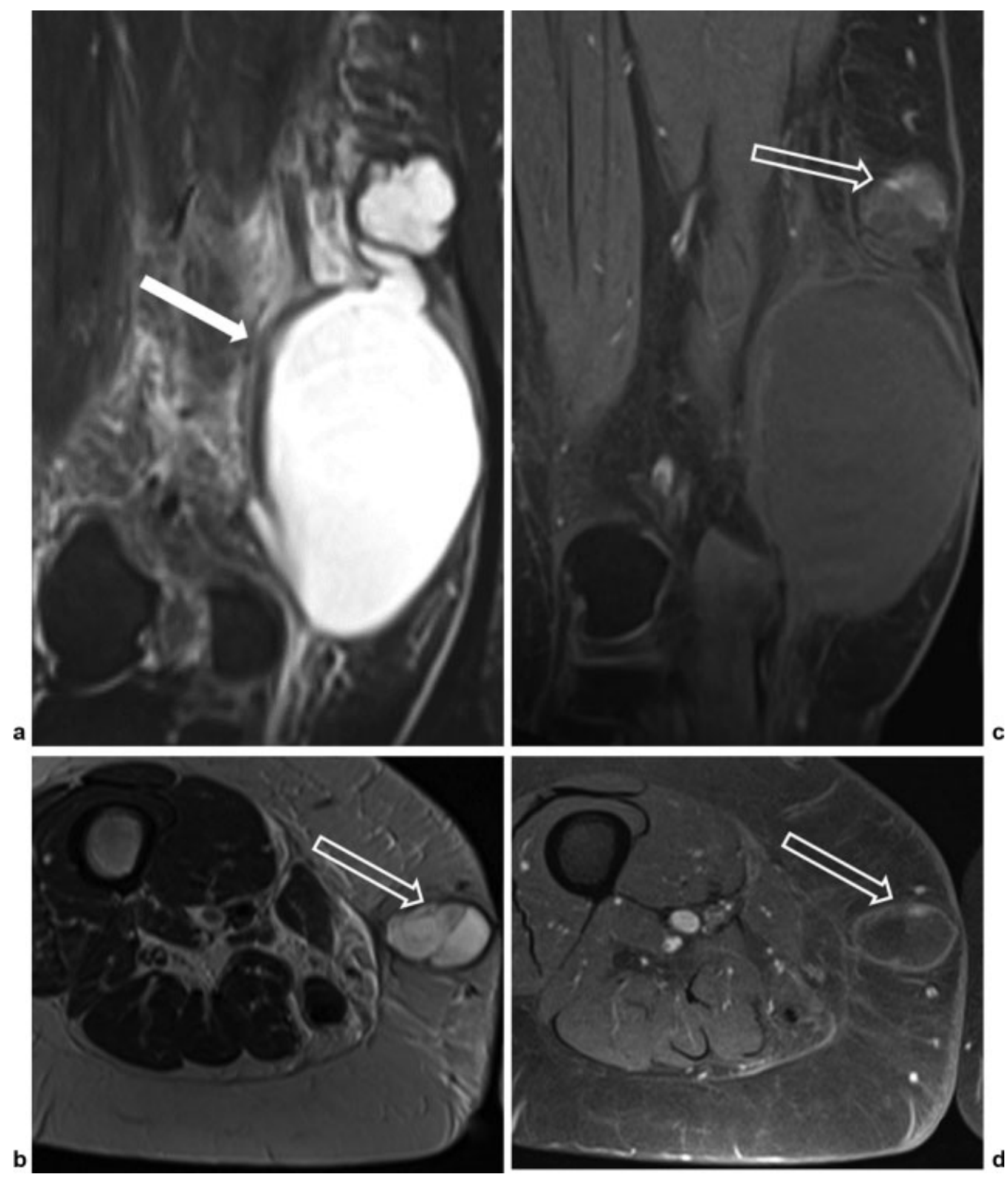

Fig. 4 Seroma with small enhancing pseudotumor. Magnetic resonance imaging (MRI) of the right distal thigh of a 79-year-old patient after initial unintended intralesional resection of leiomyosarcoma ("whoops") at an outside institution, revision, and radiation therapy. In the followup MRI, the (a) coronal short tau inversion recovery, (b) axial T2-weighted, (c) coronal, and (d) axial postcontrast T1-weighted fat-saturated sequences demonstrate a large postoperative seroma (arrow). In the proximal part of the retention, adjacent to the capsule, are small partly nodular solid intralesional components with minor contrast enhancement (open arrows), representing a pseudotumor. Histology revealed necrosis and granulation tissue.

hyperplasia of the neuronal fascicles (and was initially termed "paradoxical diffuse hypertrophy") with fiber disorganization and perineural fibrous tissue. Clear discrimination from neuroma is not possible so far. The swelling may also be related to hindrance of axonal transport. It is most pronounced distally. Continuity with the sciatic nerve proximally is a key finding in differentiation from tumor recurrence at the surgical stump. In contrast to typical stump neuroma or recurrence, the usually painless thickening is diffuse and without contrast enhancement. ${ }^{120}$

Bone complications after radiation and chemotherapy, such as osteoporosis and insufficiency fractures or osteonec- rosis, are covered elsewhere. ${ }^{121}$ We also refer to the article by Bloem et al. ${ }^{95}$

\section{Appearance of Local Recurrences and Radiation-associated Sarcomas}

\section{Local Recurrences}

LRs typically appear as masses or nodular soft tissue changes (-Fig. 4) and are usually hyperintense on fluidsensitive sequences. ${ }^{96}$ However, LR of low-grade myxofibrosarcoma and of undifferentiated pleomorphic sarcoma may appear plaque-like or show tail-like infiltration. ${ }^{122,123}$ 


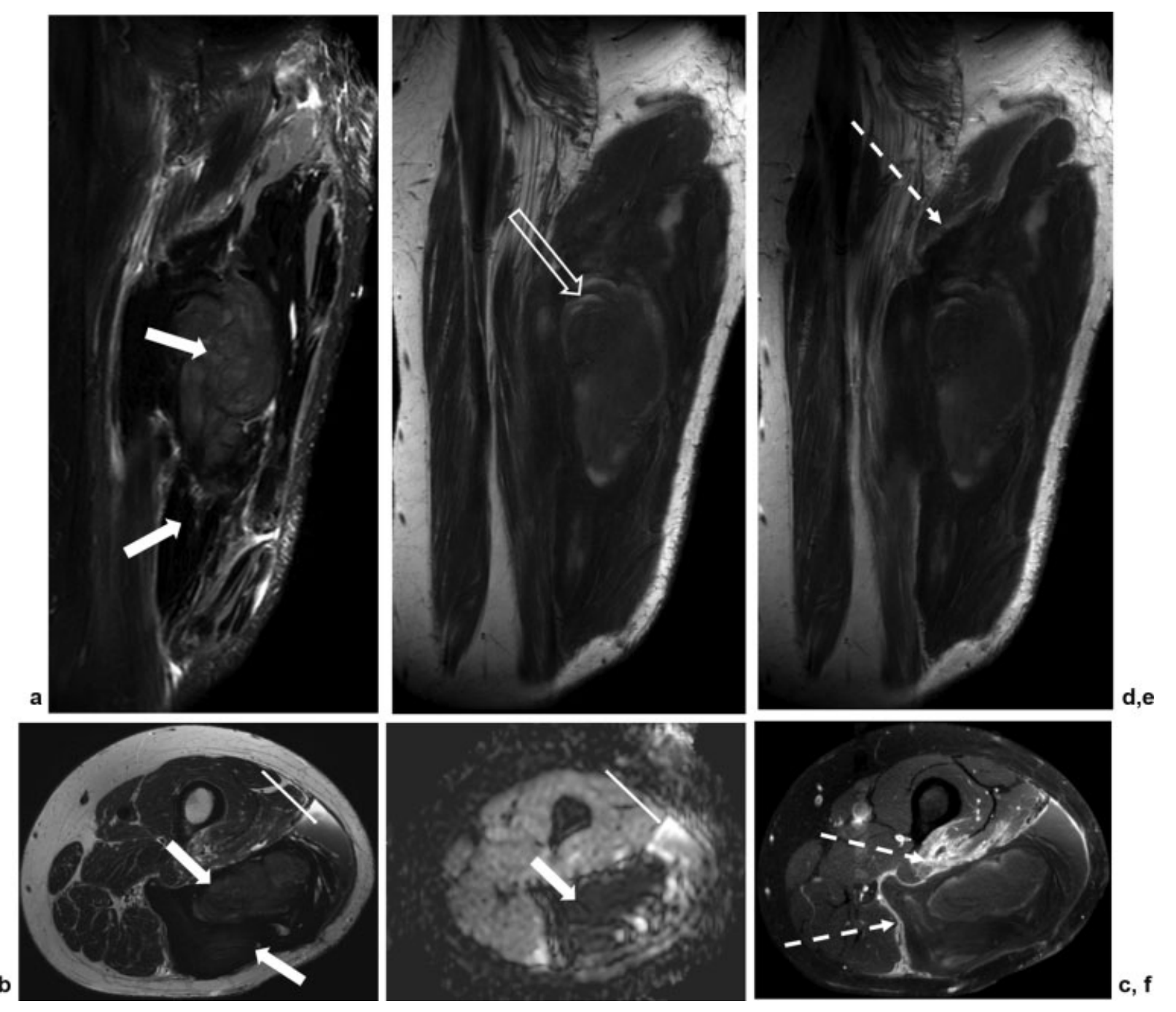

Fig. 5 Postoperative hematoma. Magnetic resonance imaging of the left thigh 1 month after resection of an undifferentiated pleomorphic sarcoma G3, in a 68-year-old male anticoagulated patient (after pulmonary embolism). Continuous bleeding from a small wound dehiscence. (a) Coronal short tau inversion recovery, (b) axial T2-weighted images, and (c) apparent diffusion coefficient map show a large hematoma with hemorrhagic elements of different ages (white arrows) and sedimentation phenomena (small white arrows). (d) Coronal T1-weighted hyperintense components can be depicted (white open arrow). In the postcontrast sequence (e) without and (f) with fat saturation, there is only minor intralesional enhancement due to minor organization but an enhancing capsule and adjacent postoperative muscle changes (dashed white arrow).

A new lesion compared with the baseline post-therapeutic examination and slowly enlarging tissue alterations are highly suspicious ${ }^{124}$ (- Figs. 11 and 12). The recurrence is often similar to the primary tumor ${ }^{125}$; for example, a myxoid tumor on liquid-sensitive sequences can look almost like a seroma (-Figs. 5 and $\mathbf{6}$ ). The morphology of the current lesion should therefore be correlated with that of the original tumor. 86,126

Circumscribed hyperintense lesions should be further clarified with T1-weighted sequences and gadolinium administration, ${ }^{127}$ preferably with the inclusion of subtraction images (-Fig. 13). The contrast-enhanced sequences prove the presence of solid tissue. The detection of arterial flooding in the tumor on the dynamic contrast sequence is particularly specific and excludes $97 \%$ of postoperative inflammatory altered or fibrotic tissue. ${ }^{78,90}$ of note, myxoid liposarcoma may almost lack contrast enhancement and FDG-PET avidity (-Fig. 14), so small recurrences may be overlooked.

As another pitfall, granulation tissue can also initially show an early contrast uptake, but after 2 to 6 months only a slow contrast uptake should then be detectable. ${ }^{128}$ A posttherapeutic baseline examination after 6 to 8 weeks therefore seems sensible, so immediate florid post-therapeutic changes can somewhat subside. ${ }^{70}$

The ADC is known to depend heavily on the tissue composition. Moreover, absolute values are highly machine dependent. The evaluation of the ADC in sarcoma follow-up MRI is therefore complex. Cell-rich sarcoma tissue usually shows a low ADC. However, the same is true for fibrosis, and myxoid sarcoma components show high ADCs. But an improvement in the specificity of the recurrence detection 

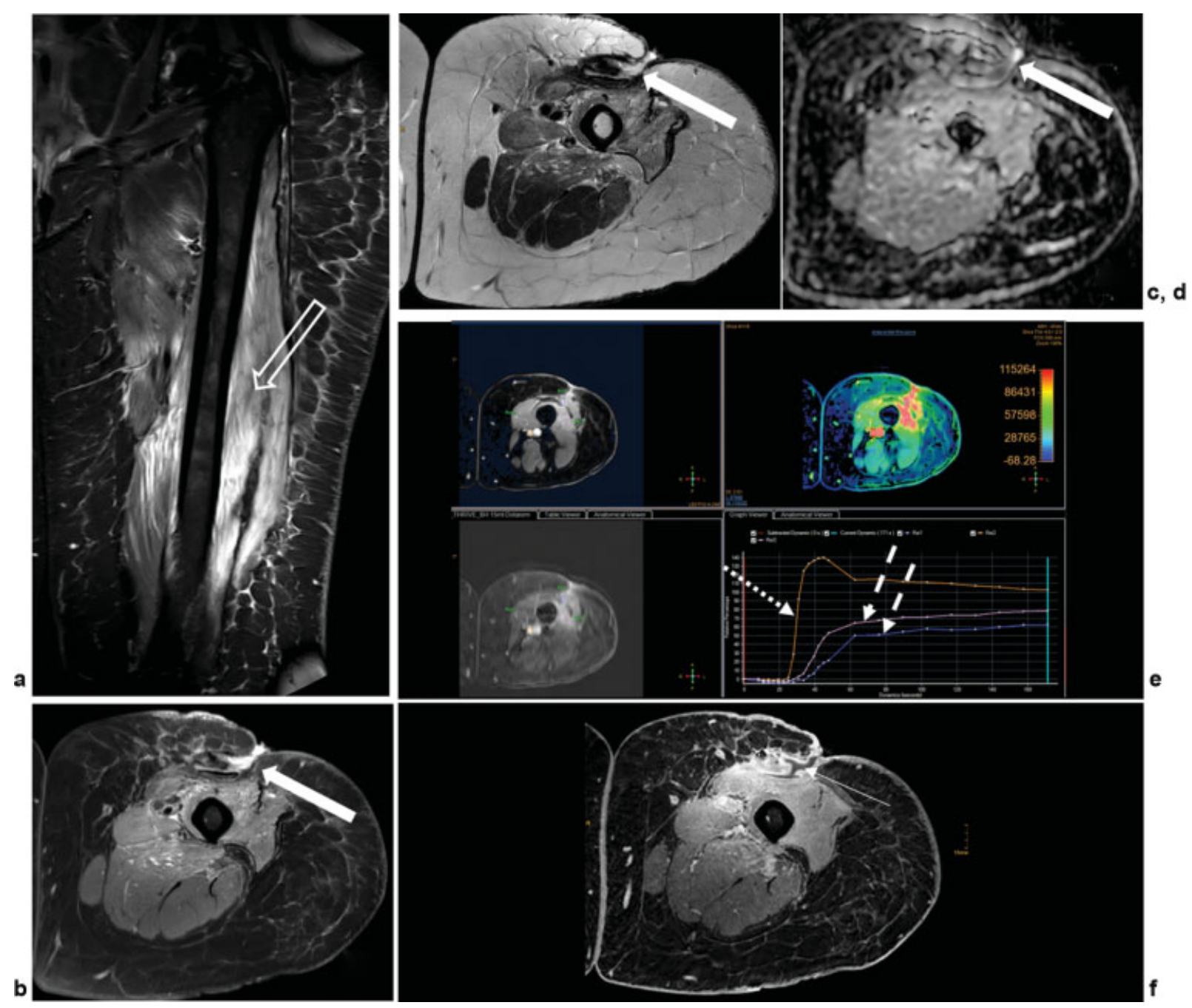

Fig. 6 Infection in a 62-year-old female patient 4 months after neoadjuvant radiotherapy and wide resection of a myxoid liposarcoma. Magnetic resonance imaging of the thigh shows postoperative wound healing disturbance with necrosis that required wound revision. (a) Coronal short tau inversion recovery, (b) axial proton-density fat-saturated (FS), (c) axial T2-weighted imaging, and (d) apparent diffusion coefficient map of diffusion-weighted imaging show the retention and a fistula (arrows) within surrounding inflammation (open arrow in (a)). (e) In the dynamic contrast-enhanced image, the diffuse enhancement of surrounding organizing inflammatory tissue (dashed arrows) is slower and begins later than the arterial curve (dotted arrow). (f) The retention does not enhance, demonstrated in the static T1-weighted FS postgadolinium sequence (small arrow).

from $52 \%$ to $97 \%$ was described when there was a region with a visually low ADC, even if this sign only occurred in $60 \%$ of the recurrences. Interestingly, the diffusion capacity of soft tissue sarcoma recurrences in one study was between that of hematomas and pseudotumors. According to this study, the ADC in pseudotumors with contrast uptake is lower than in tumor recurrence, as well as in the surrounding subcutaneous tissue (the latter presumably due to the pseudo-inflammation around the relapse tissue).$^{78}$ However, other studies plausibly describe a lower diffusion in relapse than in post-therapeutic seromas or edematous changes. ${ }^{129}$

Some tumors show special MR morphology and known high recurrence rates for which knowledge of the original tumor is vital. An example of this is the high-/dedifferentiated liposarcoma that occurs particularly in the retroperitoneum. Complete resection of the biphasic tumor is essential, that is, also the highly differentiated portion (indistinguishable from normal adipose tissue) that can also dedifferentiate in $15 \%{ }^{33,34,130}$

In aftercare, any nonlipomatous nodule formation in the retroperitoneum and mesentery is suspicious for recurrence. Relapses of retroperitoneal high-/dedifferentiated liposarcoma tend to invade the colon, diaphragm, pancreas, and small intestine. ${ }^{131}$

\section{Radiation-associated Sarcomas}

Radiation-associated or postradiation sarcomas as a differential diagnosis are rare $(0.03-0.2 \%)^{132}$ and found more often in the soft tissues than in the bones $(2.3: 1){ }^{133}$ They occur after a dose of $\sim 50 \mathrm{~Gy}$ on average and, according to the literature, ${ }^{132,134}$ typically long after radiation (on average 815.5 years) ( $\mathbf{- F i g}$. 15). Very different intervals are given: between 2 and 65 years. The latency period is somewhat 


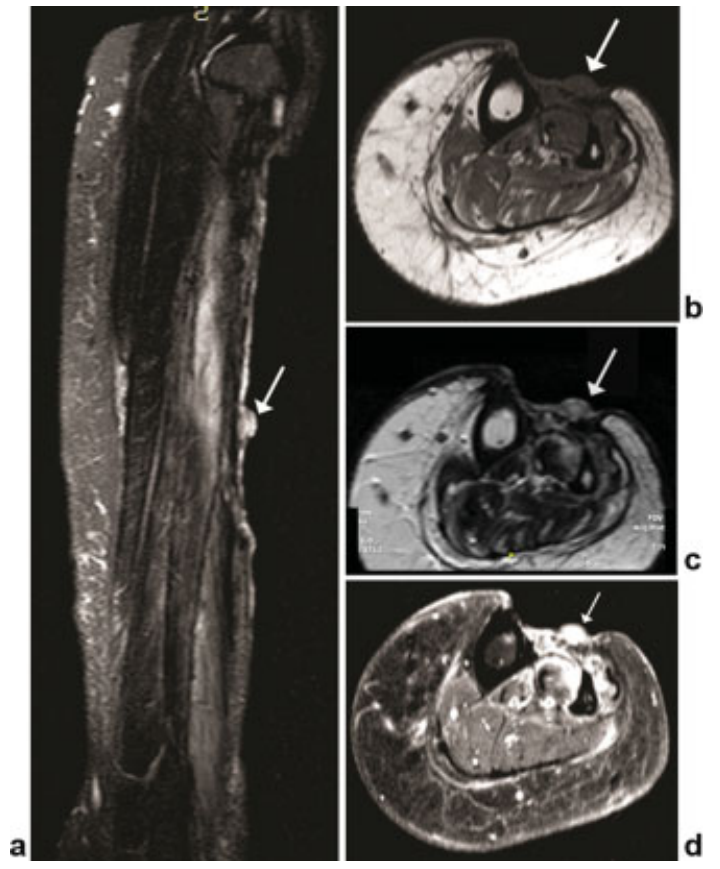

Fig. 7 Inflammatory pseudotumor in a 47-year-old woman with a history of sarcoma at the anterior aspect of the left calf, resected 3 years earlier and radiotherapy completed 2 years ago. (a) T1-weighted axial, (b) short tau inversion recovery sagittal, and (c) contrast-enhanced T1-weighted fatsaturated axial images. Diffuse edematous changes are seen at the postoperative/postradiation bed. A small nodule, with no discrete margins, projects over the skin (arrow). It is $\mathrm{T} 1$ hypointense (a), $\mathrm{T} 2$ hyperintense (d), and presents vivid delayed uptake of gadolinium (c). There are also edematous changes at the adjacent tibialis posterior and peroneal muscles (b) and mild atrophy of the gastrocnemius muscle (a). The magnetic resonance imaging study did not include dynamic administration of contrast. The nodule was resected, and histology revealed an inflammatory pseudotumor.

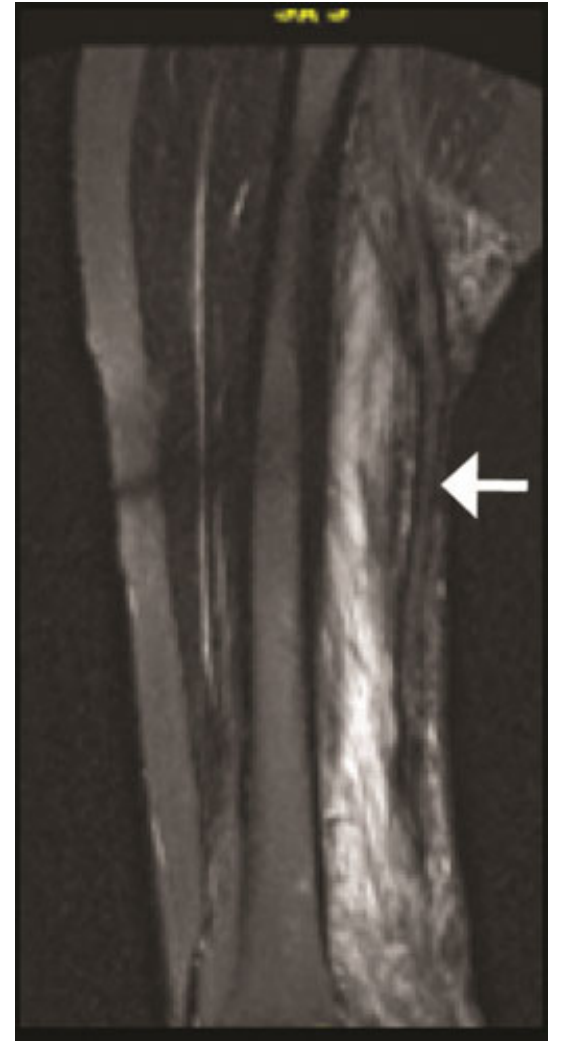

Fig. 9 Perineural fibrosis in a 31-year-old woman with a history of resected liposarcoma of the distal thigh 14 months earlier, followed by radiation therapy. A sagittal short tau inversion recovery image shows hypointense and thickened contour of the sciatic nerve, consistent with perineural fibrosis (arrow). Note the hyperintense "feathery sign" of the adjacent adductor magnus muscle.
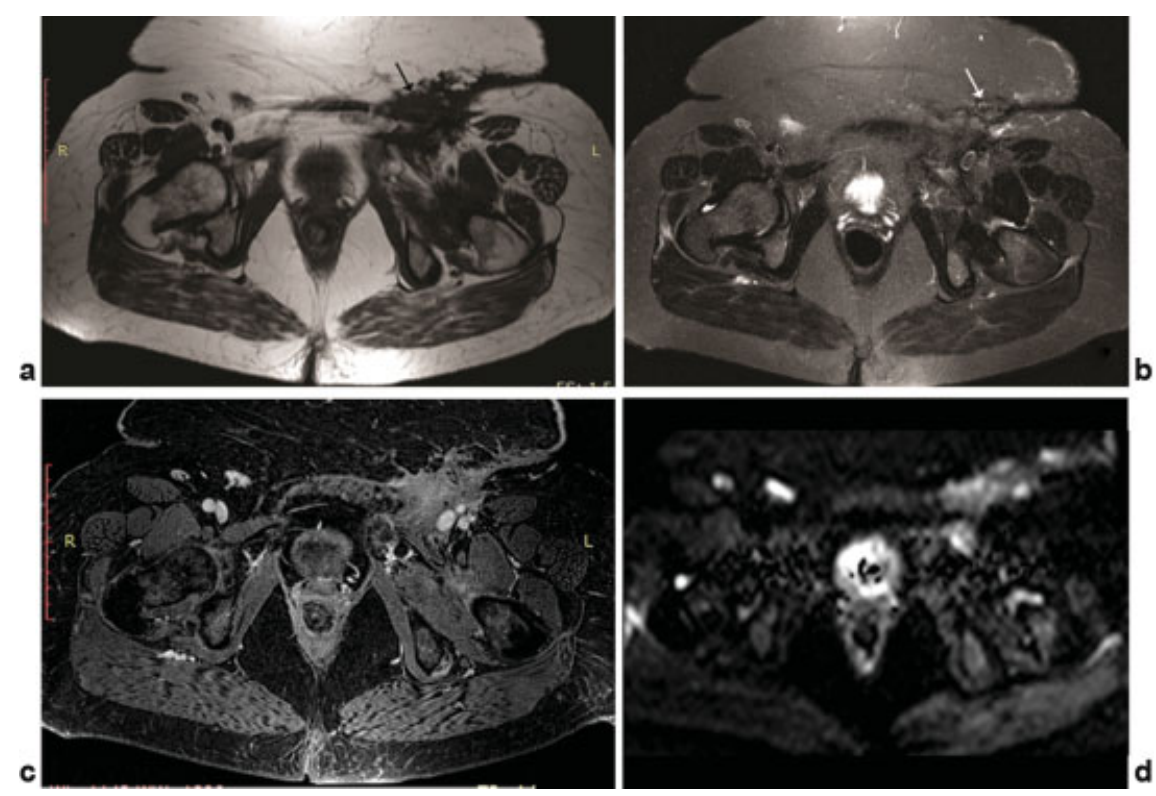

Fig. 8 Hypertrophic scar in a 60-year-old woman presented with a palpable mass at the site of a resected undifferentiated sarcoma. The resection had been performed 8 months earlier with adjuvant radiotherapy after 6 weeks. (a) T1-weighted axial image shows a homogeneous, hypointense mass-like lesion with thorny outer contour. (b) On axial T2 fat-saturated (FS) image, the lesion is mainly hypointense with moderately hyperintense transverse streaks. (c) Contrast-enhanced T1 FS image documents mild diffuse enhancement of the abnormal area with no discernible nodules. (d) The diffusion-weighted image/apparent diffusion coefficient map shows no restricted diffusion. The lesion was interpreted as hypertrophic fibrosis. Repeat surgery revealed fibrotic/granulation tissue. 


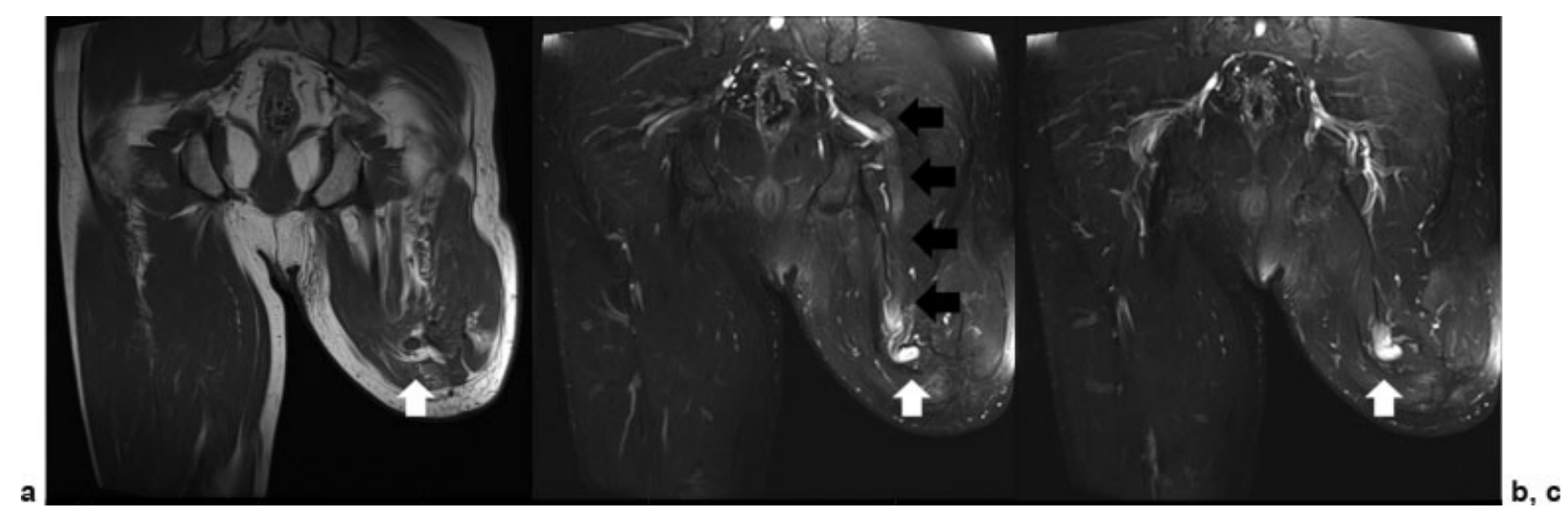

Fig. 10 Sciatic nerve swelling after amputation. Coronal magnetic resonance imaging sequences for liposarcoma in a 57-year-old male patient who underwent above-knee amputation 10 years ago, showing swelling of the distal end of the sciatic nerve (white arrow) on (a) T1-weighted, (b, c) short tau inversion recovery sequences, and the outline of the sciatic nerve (black arrows).
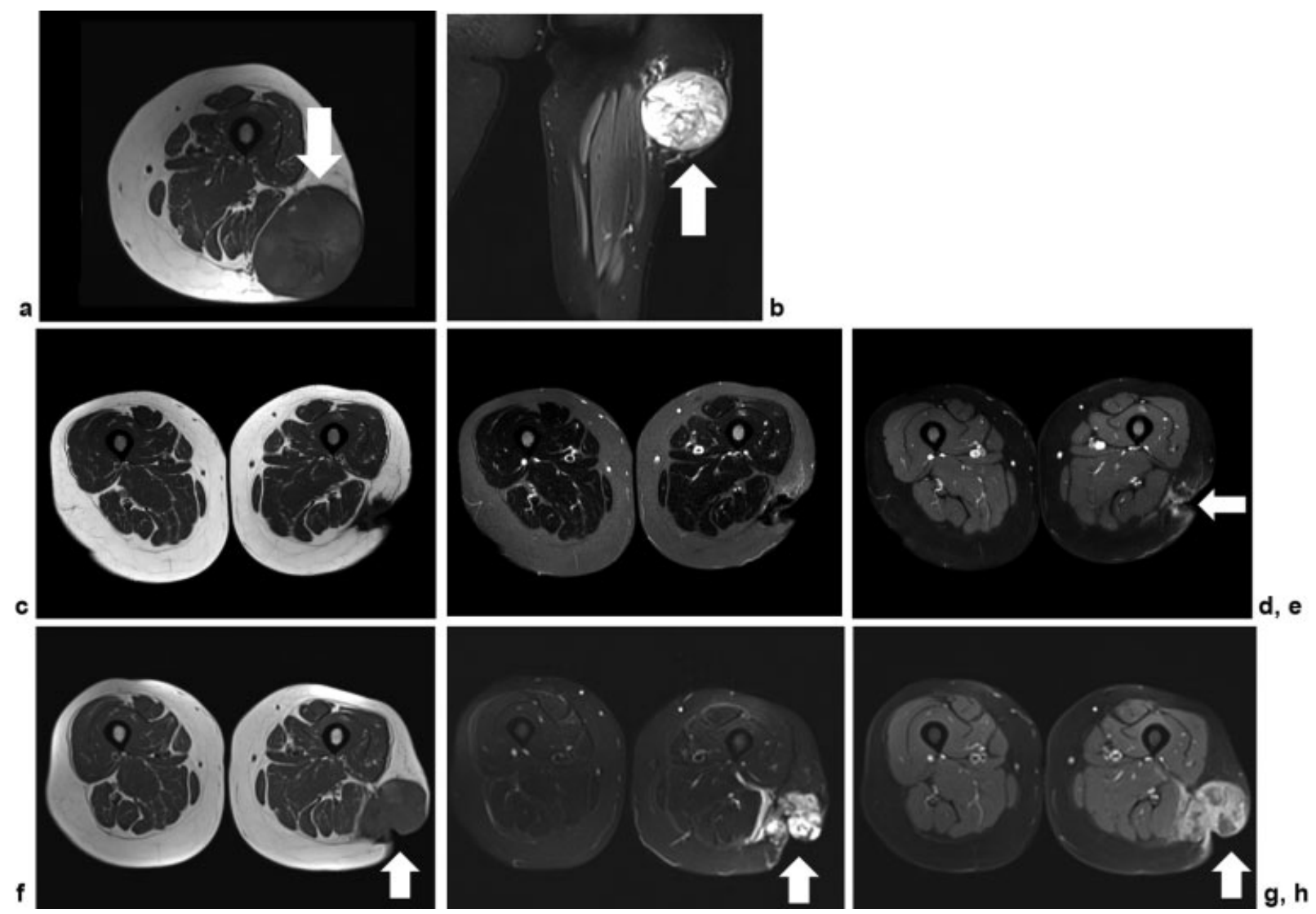

Fig. 11 Recurrence after $\mathrm{R} 1$ resection without adjuvant therapy in a 52-year-old female patient presenting with recurrence of an undifferentiated small round cell sarcoma, who had been treated externally with R1 resection without adjuvant therapy. Magnetic resonance imaging of the initial tumor at the dorsolateral aspect of the thigh had shown a sharply demarcated epifascial mass with broad contact to and minor edema-like alteration along the fascia. It was not specifically hypointense on (a) T1 and hyperintense on (b) the short tau inversion recovery (STIR) image. Follow-up 4 months postoperative, the surgical bed was hypointense on (c) T1-weighted and (d) STIR, with minor diffuse postoperative edema but with (e) nodular enhancement after contrast administration. Ten months postoperative, there is extensive local and now extracompartmental recurrence. The signal intensity is similar to the primary on (f) T1-weighted and the (g) STIR, and (h) enhances heterogeneously.

shorter in the soft tissues than in the bones. ${ }^{132,134-136}$ They express themselves as progressively growing masses. ${ }^{134,136}$

The most common radiation-associated soft tissue sarcomas are undifferentiated pleomorphic sarcomas (or the entire group of the former "malignant fibrous histiocytoma") constituting $\sim 68 \%$, followed by extraosseous osteo- sarcoma with $13 \%$. They are often poorly differentiated with a corresponding heterogeneous MR appearance ${ }^{132,134,136}$ (-Fig. 7). If new masses occur in the soft tissues or if there is bone destruction in the radiation field, after prolonged latency, differential diagnosis of sarcomas should also be considered. 

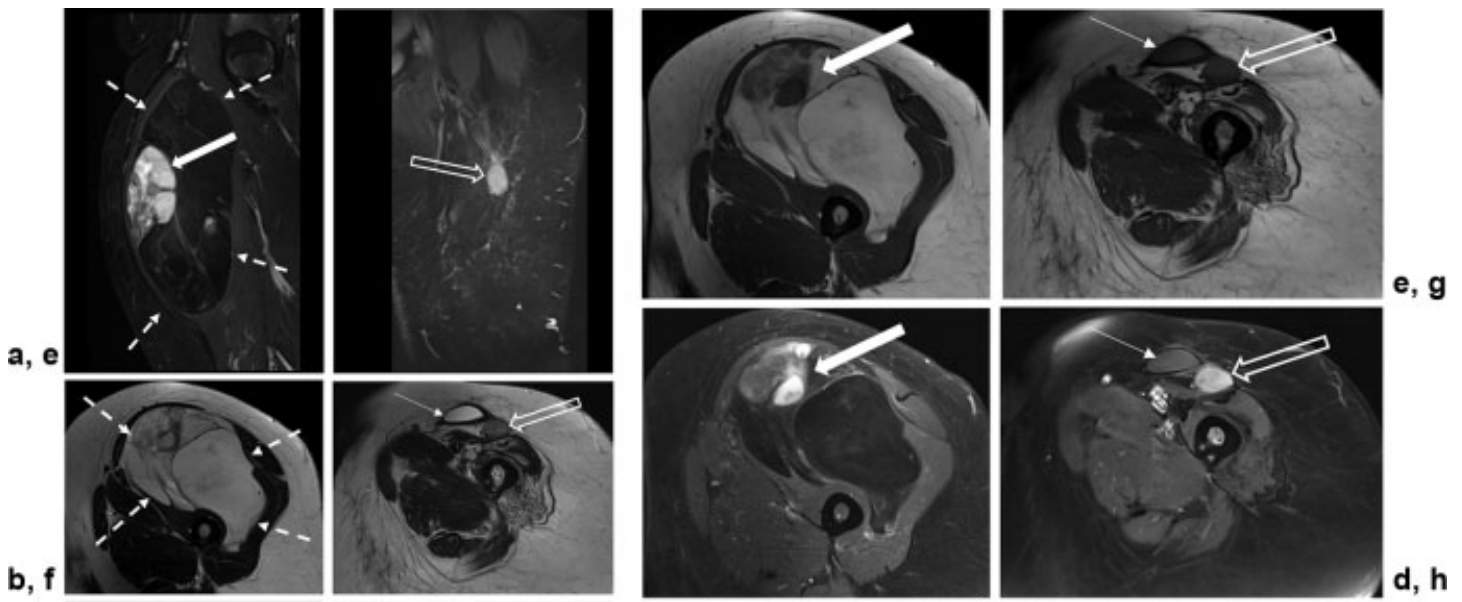

Fig. 12 Recurrence. Magnetic resonance imaging of the right thigh in a 49-year-old female patient with a high/dedifferentiated liposarcoma, with (a) sagittal short tau inversion recovery (STIR), (b) axial T2-weighted, (c) T1-weighted, and (d) T1-weighted fat-saturated (FS) postgadolinium (dashed arrows). The dedifferentiated parts of the lesion show nonfatty signal and intense contrast enhancement (arrow). The patient underwent resection and adjuvant radiotherapy. Regular follow-ups showed post-therapeutic seroma with a fibrous capsule (small arrow) and severe fatty atrophy of the quadriceps muscle. However, 6 years postsurgery, magnetic resonance imaging also reveals a recurrence that was nonpalpable (open arrows). In the (e) coronal STIR, (f) axial T2weighted, (g) T1-weighted, and (h) T1-weighted FS postgadolinium images, the new solid nodule demonstrates signal similar to the dedifferentiated primary.
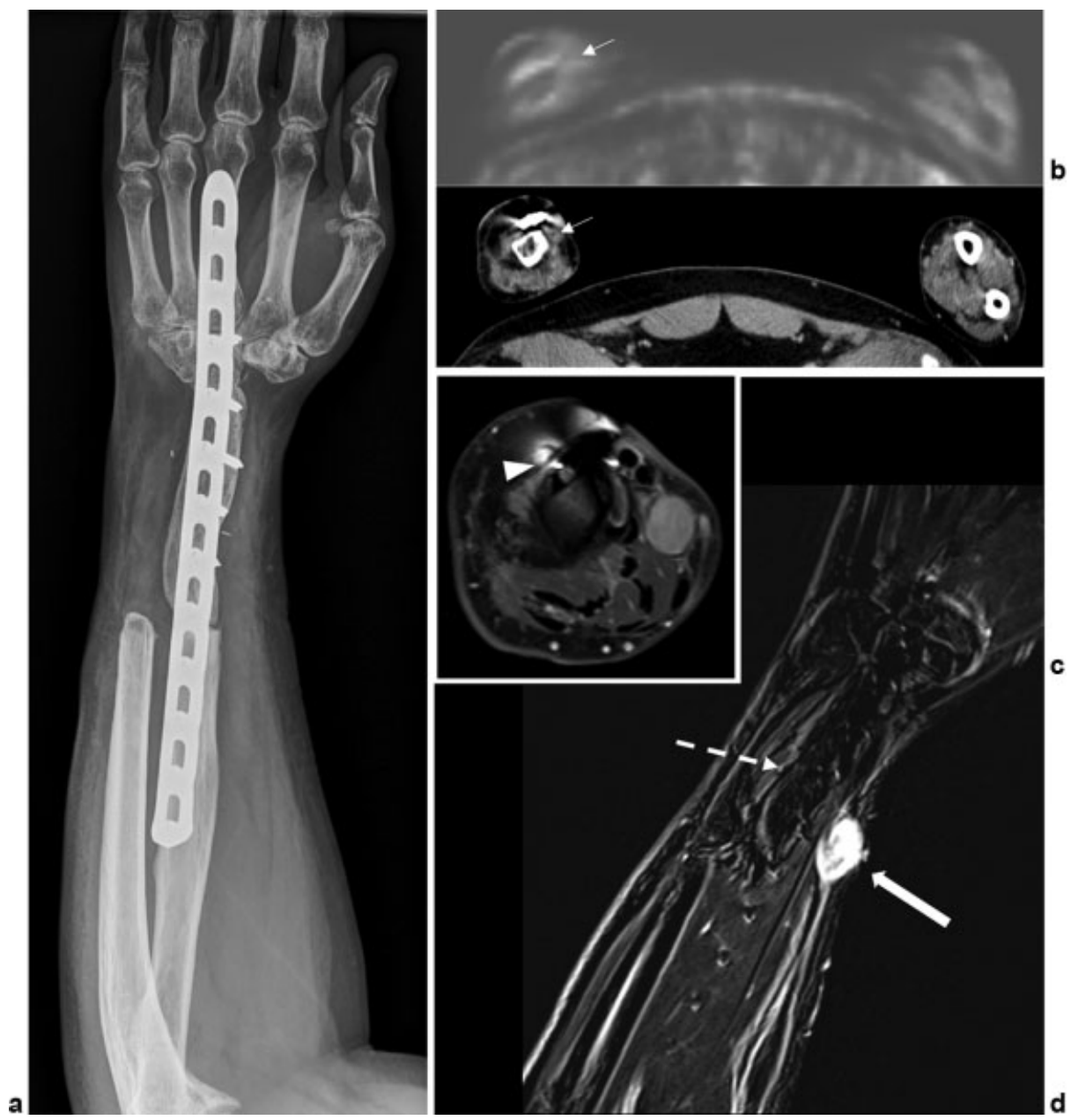

Fig.13 Recurrence and subtraction in a 33-year-old male patient, 2 years after rhabdomyosarcoma, with isolated limb perfusion and surgery, with resection, osteomyocutaneous reconstruction, and osteosynthesis (a, projection radiography). (b) Positron emission tomography/computed tomography was inconclusive (small arrows). (c) On magnetic resonance imaging, the axial fat-suppressed T1-weighted sequence postgadolinium shows the enhancing nodular recurrence (open arrow) and metal artifacts (arrowhead). (d) Postprocessing T1 subtraction with elimination of the fat signal helps better evaluate the tissue adjacent to the metallic implants. 


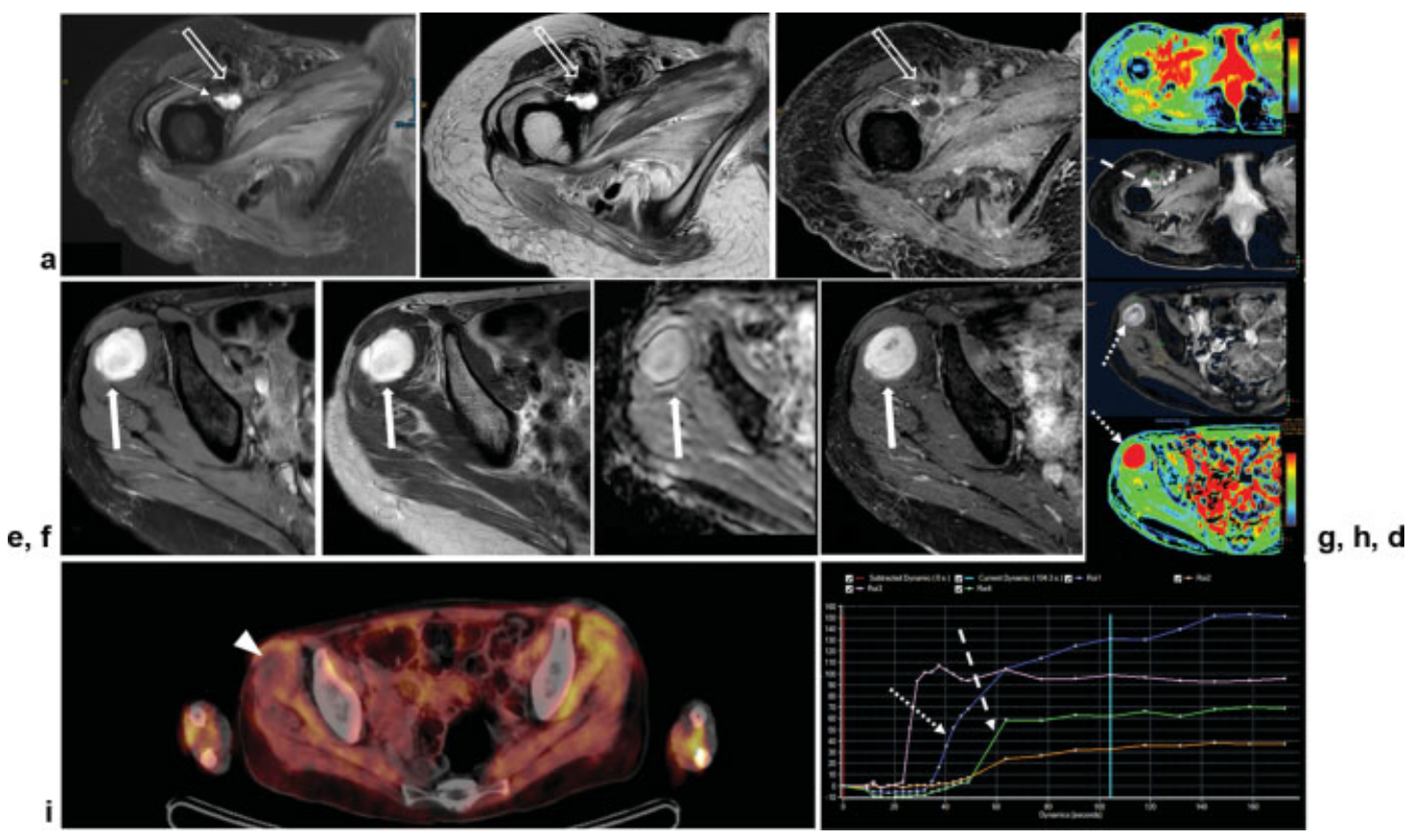

Fig. 14 Recurrence of myxoid liposarcoma in a 47-year-old woman. Magnetic resonance imaging follow-up 4 years after resection of a myxoid liposarcoma, adjuvant radiation, and wound revisions. The operation site still shows diffuse chronic inflammatory changes, a small seroma (small arrow), and fibrosis (open arrows) in the (a) proton-density (PD) fat-saturated (FS), (b) T2-weighted, and (c) T1 postcontrast FS images. (d) In the dynamic contrast-enhanced (DCE) image, the enhancement starts as late as the muscle enhancement (dashed arrow; as reference: artery with rapid wash-in, muscle enhancement with least enhancement). However, in the gluteal muscles, there is a nonpalpable recurrence (formerly soft tissue metastasis, arrow) with the typical hyperintense signal of a myxoid matrix in the (e) PD FS and (f) T2-weighted images, and no diffusion restriction in (g) the apparent diffusion coefficient map. (h) The lesion shows contrast enhancement in the T1-weighted FS sequence that starts later than the external iliac artery in the DCE sequence (d) (dotted arrow), but the wash-in curve is steep. (i) In corresponding fused fluorodeoxyglucose-positron emission tomography/computed tomography, the myxoid liposarcoma (arrowheads) is typically photopenic. The patient moved a lot, leading to diffuse PET avidity of muscle groups such as the gluteals.

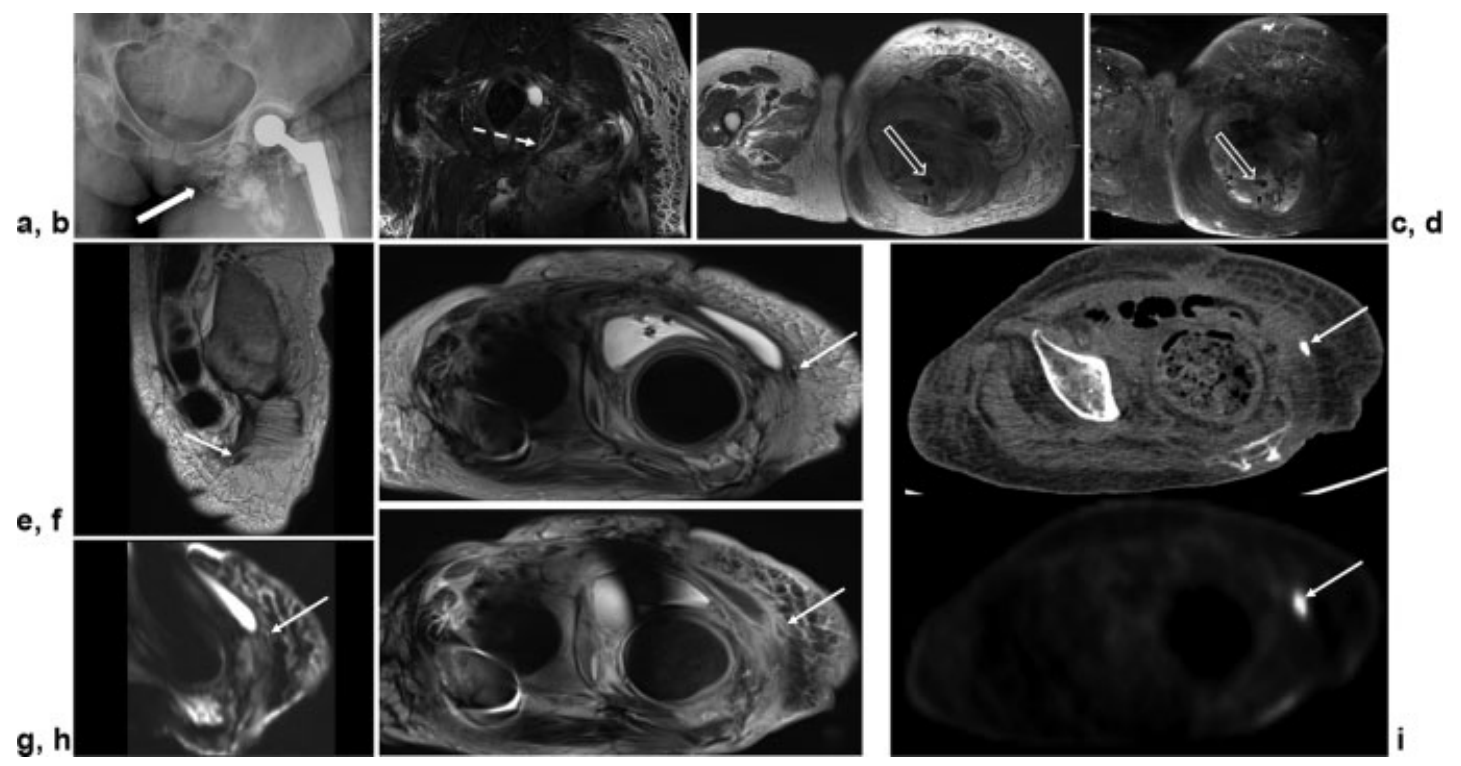

Fig. 15 Radiation-associated soft tissue sarcoma in a 71-year-old woman. Presumably radiation-associated soft tissue sarcoma (spindle cell sarcoma with highly malignant osteosarcoma component) after vulvar cancer $>10$ years ago treated with primary radiochemotherapy. (a) Projection radiography shows a large tumor with extensive calcification. Magnetic resonance imaging (MRI) of the hip and pelvis (for surgical planning) reveals local tumor extent and shows reportedly long-standing extensive lymphedema. (b) Coronal short tau inversion recovery, (c) axial T2-weighted, and (d) postcontrast fat-saturated T1-weighted images with infiltration of the pubic bone (dashed arrows) and the ischiac nerve (small arrow). The patient underwent wide resection with left-sided hemipelvectomy with gluteal flap reconstruction. One year later, magnetic resonance imaging with (e) sagittal and (f) axial T2-weighted, ( $g$ ) axial diffusion-weighted, and (h) axial postgadolinium T1-weighted fat-suppressed images reveals extensive postoperative changes with postoperative seroma and fatty atrophy of the flap. A small unspecific hypointensity (small arrow) is seen on all sequences. (i) In the corresponding fluorodeoxyglucose-positron emission tomography/computed tomography, the small lesion was mineralized and highly PET avid. Histology proved recurrence. 


\section{Conclusion}

As a rule of thumb in the recurrence detection of soft tissue tumors, the following can apply: If you first consider a T2weighted sequence with frequency-selective fat saturation, a short tau inversion recovery sequence, or the water image of a Dixon sequence, you can exclude recurrence in $99 \%$ of the cases in these situations:

- No hyperintensity is visible (such as with fibrosis in scar tissue); caution is advised for lesions such as the desmoid or the tenosynovial giant cell tumor that demonstrated hypointensity in the primary tumor;

- There is only an "edema-like" diffuse hyperintensity without a circumscribed lesion, as with post-therapeutic changes or inflammation;

- The "texture" or "feathering" pattern of muscles is visible without any other architectural disturbance, and the picture remains completely unchanged from the preliminary examination.

\section{Conflict of interest}

None declared.

\section{References}

1 Callegaro D, Miceli R, Mariani L, Raut CP, Gronchi A. Soft tissue sarcoma nomograms and their incorporation into practice. Cancer 2017;123(15):2802-2820

2 Coindre JM, Terrier P, Bui NB, et al. Prognostic factors in adult patients with locally controlled soft tissue sarcoma. A study of 546 patients from the French Federation of Cancer Centers Sarcoma Group. J Clin Oncol 1996;14(03):869-877

3 Felderhof JM, Creutzberg CL, Putter H, et al. Long-term clinical outcome of patients with soft tissue sarcomas treated with limbsparing surgery and postoperative radiotherapy. Acta Oncol 2013;52(04):745-752

4 Gronchi A, Lo Vullo S, Colombo C, et al. Extremity soft tissue sarcoma in a series of patients treated at a single institution: local control directly impacts survival. Ann Surg 2010;251(03):506-511

5 Vanhoenacker FM, Van Looveren K, Trap K, et al. Grading and characterization of soft tissue tumors on magnetic resonance imaging: the value of an expert second opinion report. Insights Imaging 2012;3(02):131-138

6 Gantzer J, Di Marco A, Fabacher T, et al. Conformity to clinical practice guidelines at initial management in adult soft tissue and visceral tumors since the implementation of the NetSarc Network in eastern France. Oncologist 2019;24(08):e775-e783

7 Sekimizu M, Ogura K, Yasunaga H, et al. Development of nomograms for prognostication of patients with primary soft tissue sarcomas of the trunk and extremity: report from the Bone and Soft Tissue Tumor Registry in Japan. BMC Cancer 2019;19(01):657

8 Zagars GK, Ballo MT, Pisters PW, et al. Prognostic factors for patients with localized soft-tissue sarcoma treated with conservation surgery and radiation therapy: an analysis of 1225 patients. Cancer 2003;97(10):2530-2543

9 Italiano A, Le Cesne A, Mendiboure J, et al. Prognostic factors and impact of adjuvant treatments on local and metastatic relapse of soft-tissue sarcoma patients in the competing risks setting. Cancer 2014;120(21):3361-3369

10 Toulmonde $\mathrm{M}$, Le Cesne A, Mendiboure J, et al. Long-term recurrence of soft tissue sarcomas: prognostic factors and implications for prolonged follow-up. Cancer 2014;120(19): 3003-3006
11 Gronchi A, Strauss DC, Miceli R, et al. Variability in patterns of recurrence after resection of primary retroperitoneal sarcoma (RPS): a report on 1007 patients from the multi-institutional collaborative RPS Working Group. Ann Surg 2016;263(05): 1002-1009

12 Smith HG, Memos N, Thomas JM, Smith MJ, Strauss DC, Hayes AJ. Patterns of disease relapse in primary extremity soft-tissue sarcoma. Br J Surg 2016;103(11):1487-1496

13 Novais EN, Demiralp B, Alderete J, Larson MC, Rose PS, Sim FH. Do surgical margin and local recurrence influence survival in soft tissue sarcomas? Clin Orthop Relat Res 2010;468(11): 3003-3011

14 Gerrand CH, Bell RS, Wunder JS, et al. The influence of anatomic location on outcome in patients with soft tissue sarcoma of the extremity. Cancer 2003;97(02):485-492

15 Qureshi YA, Huddy JR, Miller JD, Strauss DC, Thomas JM, Hayes AJ. Unplanned excision of soft tissue sarcoma results in increased rates of local recurrence despite full further oncological treatment. Ann Surg Oncol 2012;19(03):871-877

16 Wang L, Pretell-Mazzini J, Kerr DA, et al. MRI findings associated with microscopic residual tumor following unplanned excision of soft tissue sarcomas in the extremities. Skeletal Radiol 2018; 47(02):181-190

17 Sawamura C, Matsumoto S, Shimoji T, Tanizawa T, Ae K. What are risk factors for local recurrence of deep high-grade soft-tissue sarcomas? Clin Orthop Relat Res 2012;470(03):700-705

18 Traub F, Griffin AM, Wunder JS, Ferguson PC. Influence of unplanned excisions on the outcomes of patients with stage III extremity soft-tissue sarcoma. Cancer 2018;124(19):3868-3875

19 Sabolch A, Feng M, Griffith K, et al. Risk factors for local recurrence and metastasis in soft tissue sarcomas of the extremity. Am J Clin Oncol 2012;35(02):151-157

20 Trovik CS, Bauer HC, Alvegård TA, et al. Surgical margins, local recurrence and metastasis in soft tissue sarcomas: 559 surgically-treated patients from the Scandinavian Sarcoma Group Register. Eur J Cancer 2000;36(06):710-716

21 Alamanda VK, Crosby SN, Archer KR, Song Y, Schwartz HS, Holt GE. Predictors and clinical significance of local recurrence in extremity soft tissue sarcoma. Acta Oncol 2013;52(04):793-802

22 Stojadinovic A, Leung DH, Hoos A, Jaques DP, Lewis JJ, Brennan MF. Analysis of the prognostic significance of microscopic margins in 2,084 localized primary adult soft tissue sarcomas. Ann Surg 2002;235(03):424-434

23 Daigeler A, Zmarsly I, Hirsch T, et al. Long-term outcome after local recurrence of soft tissue sarcoma: a retrospective analysis of factors predictive of survival in 135 patients with locally recurrent soft tissue sarcoma. Br J Cancer 2014;110(06):1456-1464

24 Liu CY, Yen CC, Chen WM, et al. Soft tissue sarcoma of extremities: the prognostic significance of adequate surgical margins in primary operation and reoperation after recurrence. Ann Surg Oncol 2010;17(08):2102-2111

25 Gundle KR, Gupta S, Kafchinski L, et al. An analysis of tumor- and surgery-related factors that contribute to inadvertent positive margins following soft tissue sarcoma resection. Ann Surg Oncol 2017;24(08):2137-2144

26 Shapeero LG, De Visschere PJ, Verstraete KL, et al. Post-treatment complications of soft tissue tumours. Eur J Radiol 2009;69(02): 209-221

27 Lazarides AL, Kerr DL, Nussbaum DP, et al. Soft tissue sarcoma of the extremities: what is the value of treating at high-volume centers? Clin Orthop Relat Res 2019;477(04):718-727

28 Benson C, Judson I. Role of expert centres in the management of sarcomas-a UK perspective. Eur J Cancer 2014;50(11):1951-1956

29 Bagaria SP, Chang YH, Gray RJ, Ashman JB, Attia S, Wasif N. Improving long-term outcomes for patients with extra-abdominal soft tissue sarcoma regionalization to high-volume centers, improved compliance with guidelines or both? Sarcoma 2018; 2018:8141056 
30 Salas S, Stoeckle E, Collin F, et al. Superficial soft tissue sarcomas (S-STS): a study of 367 patients from the French Sarcoma Group (FSG) database. Eur J Cancer 2009;45(12):2091-2102

31 Eilber FC, Rosen G, Nelson SD, et al. High-grade extremity soft tissue sarcomas: factors predictive of local recurrence and its effect on morbidity and mortality. Ann Surg 2003;237(02):218-226

32 Grobmyer SR, Brennan MF. Predictive variables detailing the recurrence rate of soft tissue sarcomas. Curr Opin Oncol 2003;15 (04):319-326

33 Singer S, Antonescu CR, Riedel E, Brennan MF. Histologic subtype and margin of resection predict pattern of recurrence and survival for retroperitoneal liposarcoma. Ann Surg 2003;238 (03):358-370; discussion 370-371

34 Peterson JJ, Kransdorf MJ, Bancroft LW, O'Connor MI. Malignant fatty tumors: classification, clinical course, imaging appearance and treatment. Skeletal Radiol 2003;32(09):493-503

35 Zagars GK, Ballo MT, Pisters PW, Pollock RE, Patel SR, Benjamin RS. Prognostic factors for disease-specific survival after first relapse of soft-tissue sarcoma: analysis of 402 patients with disease relapse after initial conservative surgery and radiotherapy. Int J Radiat Oncol Biol Phys 2003;57(03):739-747

36 Nakamura T, Abudu A, Murata H, et al. Oncological outcome of patients with deeply located soft tissue sarcoma of the pelvis: a follow up study at minimum 5 years after diagnosis. Eur J Surg Oncol 2013;39(09):1030-1035

37 Abatzoglou S, Turcotte RE, Adoubali A, Isler MH, Roberge D. Local recurrence after initial multidisciplinary management of soft tissue sarcoma: is there a way out? Clin Orthop Relat Res 2010; 468(11):3012-3018

38 Willems SM, Debiec-Rychter M, Szuhai K, Hogendoorn PC, Sciot R. Local recurrence of myxofibrosarcoma is associated with increase in tumour grade and cytogenetic aberrations, suggesting a multistep tumour progression model. Mod Pathol 2006;19(03):407-416

39 Fox MG, Bancroft LW, Peterson JJ, Kransdorf MJ, Terkonda SP, O'Connor MI. MRI appearance of myocutaneous flaps commonly used in orthopedic reconstructive surgery. AJR Am J Roentgenol 2006;187(03):800-806

40 Magerkurth O, Girish G, Jacobson JA, et al. MR imaging appearances of soft tissue flaps following reconstructive surgery of the lower extremity. Korean J Radiol 2015;16(01):160-168

41 Ghert MA, Davis AM, Griffin AM, et al. The surgical and functional outcome of limb-salvage surgery with vascular reconstruction for soft tissue sarcoma of the extremity. Ann Surg Oncol 2005;12(12):1102-1110

42 Parrett BM, Talbot SG, Pribaz JJ, Lee BT. A review of local and regional flaps for distal leg reconstruction. J Reconstr Microsurg 2009;25(07):445-455

43 Summer T, Bota O, Armbruster R, Münchow S, Dragu A. Soft tissue defects following tumor resection in the limbs and trunk: plastic reconstructive soft tissue and revision concepts. [in German]. Orthopade 2020;49(02):169-176

44 Wortman JR, Tirumani SH, Jagannathan JP, et al. Radiation therapy for soft-tissue sarcomas: a primer for radiologists. Radiographics 2016;36(02):554-572

45 Jebsen NL, Trovik CS, Bauer HC, et al. Radiotherapy to improve local control regardless of surgical margin and malignancy grade in extremity and trunk wall soft tissue sarcoma: a Scandinavian sarcoma group study. Int J Radiat Oncol Biol Phys 2008;71(04): 1196-1203

46 Sampath S, Hitchcock YJ, Shrieve DC, Randall RL, Schultheiss TE, Wong JY. Radiotherapy and extent of surgical resection in retroperitoneal soft-tissue sarcoma: multi-institutional analysis of 261 patients. J Surg Oncol 2010;101(05):345-350

47 Davis AM, O'Sullivan B, Turcotte R, et al; Canadian Sarcoma Group NCI Canada Clinical Trial Group Randomized Trial. Late radiation morbidity following randomization to preoperative versus postoperative radiotherapy in extremity soft tissue sarcoma. Radiother Oncol 2005;75(01):48-53
48 O'Sullivan B, Davis A. Five-year results of a randomized phase III trial of pre-operative vs postoperative radiotherapy in extremity soft tissue sarcoma. J Clin Oncol 2004;22(9007):

49 Choong PF, Petersen IA, Nascimento AG, Sim FH. Is radiotherapy important for low-grade soft tissue sarcoma of the extremity? Clin Orthop Relat Res 2001;(387):191-199

50 Kraus-Tiefenbacher US, Van Kampen M. Current trends in radiotherapy following surgical resection of soft-tissue sarcoma of the extremities and trunk. [in German]. Handchir Mikrochir Plast Chir 2015;47(02):128-133

51 Zagars GK, Ballo MT, Pisters PW, Pollock RE, Patel SR, Benjamin RS. Preoperative vs. postoperative radiation therapy for soft tissue sarcoma: a retrospective comparative evaluation of disease outcome. Int J Radiat Oncol Biol Phys 2003;56(02):482-488

52 O'Sullivan B, Davis AM, Turcotte R, et al. Preoperative versus postoperative radiotherapy in soft-tissue sarcoma of the limbs: a randomised trial. Lancet 2002;359(9325):2235-2241

53 Barkley HT Jr, Martin RG, Romsdahl MM, Lindberg R, Zagars GK. Treatment of soft tissue sarcomas by preoperative irradiation and conservative surgical resection. Int J Radiat Oncol Biol Phys 1988;14(04):693-699

54 Cannon CP, Ballo MT, Zagars GK, et al. Complications of combined modality treatment of primary lower extremity soft-tissue sarcomas. Cancer 2006;107(10):2455-2461

55 Slump J, Bastiaannet E, Halka A, et al. Risk factors for postoperative wound complications after extremity soft tissue sarcoma resection: a systematic review and meta-analyses. J Plast Reconstr Aesthet Surg 2019;72(09):1449-1464

56 Kepka L, DeLaney TF, Suit HD, Goldberg SI. Results of radiation therapy for unresected soft-tissue sarcomas. Int J Radiat Oncol Biol Phys 2005;63(03):852-859

57 Brodowicz T, Schwameis E, Widder J, et al. Intensified adjuvant IFADIC chemotherapy for adult soft tissue sarcoma: a prospective randomized feasibility trial. Sarcoma 2000;4(04): $151-160$

58 Woll PJ, Reichardt P, Le Cesne A, et al; EORTC Soft Tissue and Bone Sarcoma Group and the NCIC Clinical Trials Group Sarcoma Disease Site Committee. Adjuvant chemotherapy with doxorubicin, ifosfamide, and lenograstim for resected soft-tissue sarcoma (EORTC 62931): a multicentre randomised controlled trial. Lancet Oncol 2012;13(10):1045-1054

59 Frustaci S, Gherlinzoni F, De Paoli A, et al. Adjuvant chemotherapy for adult soft tissue sarcomas of the extremities and girdles: results of the Italian randomized cooperative trial. J Clin Oncol $2001 ; 19(05): 1238-1247$

60 Chou YS, Liu CY, Chen WM, et al. Follow-up after primary treatment of soft tissue sarcoma of extremities: impact of frequency of follow-up imaging on disease-specific survival. J Surg Oncol 2012;106(02):155-161

61 Cheney MD, Giraud C, Goldberg SI, et al. MRI surveillance following treatment of extremity soft tissue sarcoma. J Surg Oncol 2014;109(06):593-596

62 Hovgaard TB, Nymark T, Skov O, Petersen MM. Follow-up after initial surgical treatment of soft tissue sarcomas in the extremities and trunk wall. Acta Oncol 2017;56(07):1004-1012

63 Park JW, Yoo HJ, Kim HS, et al. MRI surveillance for local recurrence in extremity soft tissue sarcoma. Eur J Surg Oncol 2019;45(02):268-274

64 George A, Grimer RJ, James SLJ. Could routine magnetic resonance imaging detect local recurrence of musculoskeletal sarcomas earlier? a cost-effectiveness study. Indian J Orthop 2018;52 (01):81-86

65 Hirschmann A, van Praag VM, Haas RL, van de Sande MAJ, Bloem JL. Can we use MRI to detect clinically silent recurrent soft-tissue sarcoma? Eur Radiol 2020;30(09):4724-4733

66 Patel SA, Royce TJ, Barysauskas CM, Thornton KA, Raut CP, Baldini EH. Surveillance imaging patterns and outcomes following radiation therapy and radical resection for localized extremity 
and trunk soft tissue sarcoma. Ann Surg Oncol 2017;24(06): 1588-1595

67 Cormier JN, Pollock RE. Soft tissue sarcomas. CA Cancer J Clin 2004;54(02):94-109

68 Gibbs JF, Lee RJ, Driscoll DL, McGrath BE, Mindell ER, Kraybill WG. Clinical importance of late recurrence in soft-tissue sarcomas. J Surg Oncol 2000;73(02):81-86

69 Maretty-Nielsen K, Aggerholm-Pedersen N, Safwat A, et al. Prognostic factors for local recurrence and mortality in adult soft tissue sarcoma of the extremities and trunk wall: a cohort study of 922 consecutive patients. Acta Orthop 2014;85(03): 323-332

70 Roberts CC, Kransdorf MJ, Beaman FD, et al. ACR appropriateness criteria follow-up of malignant or aggressive musculoskeletal tumors. J Am Coll Radiol 2016;13(04):389-400

71 Casali PG, Abecassis N, Aro HT, et al; ESMO Guidelines Committee and EURACAN. Soft tissue and visceral sarcomas: ESMOEURACAN Clinical Practice Guidelines for diagnosis, treatment and follow-up. Ann Oncol 2018;29(Suppl 4):iv51-iv67

72 Noebauer-Huhmann IM, Weber MA, Lalam RK, et al. Soft tissue tumors in adults: ESSR-approved guidelines for diagnostic imaging. Semin Musculoskelet Radiol 2015;19(05):475-482

73 Mehren MV. NCCN clinical practice guidelines in oncology (NCCN Guidelines ${ }^{\circledR}$ ). Soft tissue sarcoma 2019; Available at: https://www.nccn.org/professionals/physician_gls/pdf/sarcoma. pdf. Accessed November 20, 2020

74 Nöbauer-Huhmann IM. Soft tissue tumors: imaging strategy for local primary diagnostics-manifestation, pearls and pitfalls in MRI. [in German]. Radiologe 2014;54(08):803-818

75 Yahya Zaidi M, Cardona K. Post-operative surveillance in soft tissue sarcoma: using tumor-specific recurrence patterns to direct approach. Linchuang Zhongliuxue Zazhi 2018;7(04):45

76 Tan MC, Brennan MF, Kuk D, et al. Histology-based classification predicts pattern of recurrence and improves risk stratification in primary retroperitoneal sarcoma. Ann Surg 2016;263(03): 593-600

77 Park SY, Chung HW, Chae SY, Lee JS. Comparison of MRI and PETCT in detecting the loco-regional recurrence of soft tissue sarcomas during surveillance. Skeletal Radiol 2016;45(10): $1375-1384$

78 Del Grande F, Subhawong T, Weber K, Aro M, Mugera C, Fayad LM. Detection of soft-tissue sarcoma recurrence: added value of functional MR imaging techniques at 3.0 T. Radiology 2014; 271(02):499-511

79 Choi H, Varma DG, Fornage BD, Kim EE, Johnston DA. Soft-tissue sarcoma: MR imaging vs sonography for detection of local recurrence after surgery. AJR Am J Roentgenol 1991;157(02):353-358

80 Tagliafico A, Truini M, Spina B, et al. Follow-up of recurrences of limb soft tissue sarcomas in patients with localized disease: performance of ultrasound. Eur Radiol 2015;25(09):2764-2770

81 Piperkova E, Mikhaeil M, Mousavi A, et al. Impact of PET and CT in PET/CT studies for staging and evaluating treatment response in bone and soft tissue sarcomas. Clin Nucl Med 2009;34(03):146-150

82 Lim HJ, Johnny Ong CA, Tan JW, Ching Teo MC. Utility of positron emission tomography/computed tomography (PET/CT) imaging in the evaluation of sarcomas: a systematic review. Crit Rev Oncol Hematol 2019;143:1-13

83 Van Rijswijk CSP, Bloem JL. Follow-up imaging of soft tissue tumors. In: Vanhoenacker FM, Parizel PM, Gielen JL, eds. Imaging of Soft Tissue Tumors. 4th ed. New York, NY: Springer International; 2017

84 Dürr HR, Rauh J, Baur-Melnyk A, et al. Myxoid liposarcoma: local relapse and metastatic pattern in 43 patients. BMC Cancer 2018; 18(01):304

85 Erfanian Y, Grueneisen J, Kirchner J, et al. Integrated 18F-FDG PET/MRI compared to MRI alone for identification of local recurrences of soft tissue sarcomas: a comparison trial. Eur J Nucl Med Mol Imaging 2017;44(11):1823-1831
86 Garner HW, Kransdorf MJ, Peterson JJ. Posttherapy imaging of musculoskeletal neoplasms. Radiol Clin North Am 2011;49(06): 1307-1323, vii

87 Amini B, Murphy WA, Haygood TM, et al. Gadolinium-based contrast agents improve detection of recurrent soft-tissue sarcoma at MRI. Available at: https://pubs.rsna.org/doi/10.1148/ rycan.2020190046. Accessed November 20, 2020

88 Papakonstantinou O, Isaac A, Dalili D, Noebauer-Huhmann IM. T2-weighted hypointense tumors and tumor-like lesions. Semin Musculoskelet Radiol 2019;23(01):58-75

89 Pezeshk P, Alian A, Chhabra A. Role of chemical shift and Dixon based techniques in musculoskeletal MR imaging. Eur J Radiol 2017;94:93-100

90 Vanel D, Shapeero LG, Tardivon A, Western A, Guinebretière JM. Dynamic contrast-enhanced MRI with subtraction of aggressive soft tissue tumors after resection. Skeletal Radiol 1998;27(09):505-510

91 Tagliafico AS, Bignotti B, Rossi F, Valdora F, Martinoli C. Local recurrence of soft tissue sarcoma: a radiomic analysis. Radiol Oncol 2019;53(03):300-306

92 Kransdorf MJ, Murphey MD. Imaging of Soft Tissue Tumors. 2nd ed. Philadelphia, PA: Lippincott Williams \& Wilkins; 2006:38-79

93 Richardson ML, Zink-Brody GC, Patten RM, Koh WJ, Conrad EU. MR characterization of post-irradiation soft tissue edema. Skeletal Radiol 1996;25(06):537-543

94 Garner HW, Kransdorf MJ, Bancroft LW, Peterson JJ, Berquist TH, Murphey MD. Benign and malignant soft-tissue tumors: posttreatment MR imaging. Radiographics 2009;29(01):119-134

95 Bloem J, Vriens D, Krol A, et al. Therapy-related imaging findings in patients with sarcoma. Semin Musculoskelet Radiol 2020;24 (06):676-691

96 Vanel D, Shapeero LG, De Baere T, et al. MR imaging in the followup of malignant and aggressive soft-tissue tumors: results of 511 examinations. Radiology 1994;190(01):263-268

97 Biondetti PR, Ehman RL. Soft-tissue sarcomas: use of textural patterns in skeletal muscle as a diagnostic feature in postoperative MR imaging. Radiology 1992;183(03):845-848

98 Vanel D, Lacombe MJ, Couanet D, Kalifa C, Spielmann M, Genin J. Musculoskeletal tumors: follow-up with MR imaging after treatment with surgery and radiation therapy. Radiology 1987;164 (01):243-245

99 Hwang S, Lefkowitz R, Landa J, et al. Local changes in bone marrow at MRI after treatment of extremity soft tissue sarcoma. Skeletal Radiol 2009;38(01):11-19

100 Stevens SK, Moore SG, Kaplan ID. Early and late bone-marrow changes after irradiation: MR evaluation. AJR Am J Roentgenol 1990;154(04):745-750

101 Blomlie V, Rofstad EK, Skjønsberg A, Tverå K, Lien HH. Female pelvic bone marrow: serial MR imaging before, during, and after radiation therapy. Radiology 1995;194(02):537-543

102 Casamassima F, Ruggiero C, Caramella D, Tinacci E, Villari N, Ruggiero M. Hematopoietic bone marrow recovery after radiation therapy: MRI evaluation. Blood 1989;73(06):1677-1681

103 Peat BG, Bell RS, Davis A, et al. Wound-healing complications after soft-tissue sarcoma surgery. Plast Reconstr Surg 1994;93 (05):980-987

104 Baldini EH, Lapidus MR, Wang Q et al. Predictors for major wound complications following preoperative radiotherapy and surgery for soft-tissue sarcoma of the extremities and trunk: importance of tumor proximity to skin surface. Ann Surg Oncol 2013;20(05):1494-1499

105 Davies AM, Vanel D. Follow-up of musculoskeletal tumors. I. Local recurrence. Eur Radiol 1998;8(05):791-799

106 Poon-Chue A, Menendez L, Gerstner MM, Colletti P, Terk M. MRI evaluation of post-operative seromas in extremity soft tissue sarcomas. Skeletal Radiol 1999;28(05):279-282

107 Liu PT, Leslie KO, Beauchamp CP, Cherian SF. Chronic expanding hematoma of the thigh simulating neoplasm on gadoliniumenhanced MRI. Skeletal Radiol 2006;35(04):254-257 
108 Aoki T, Nakata $\mathrm{H}$, Watanabe $\mathrm{H}$, et al. The radiological findings in chronic expanding hematoma. Skeletal Radiol 1999;28(07): 396-401

109 Oka K, Yakushiji T, Sato H, et al. Ability of diffusion-weighted imaging for the differential diagnosis between chronic expanding hematomas and malignant soft tissue tumors. J Magn Reson Imaging 2008;28(05):1195-1200

110 Reid JD, Kommareddi S, Lankerani M, Park MC. Chronic expanding hematomas. A clinicopathologic entity. JAMA 1980;244(21): 2441-2442

111 Nagano S, Yokouchi M, Setoguchi T, et al. Analysis of surgical site infection after musculoskeletal tumor surgery: risk assessment using a new scoring system. Sarcoma 2014;2014:645496

112 Soldatos T, Durand DJ, Subhawong TK, Carrino JA, Chhabra A. Magnetic resonance imaging of musculoskeletal infections: systematic diagnostic assessment and key points. Acad Radiol 2012; 19(11):1434-1443

113 Lalam RK, Cassar-Pullicino VN, Tins BJ. Magnetic resonance imaging of appendicular musculoskeletal infection. Top Magn Reson Imaging 2007;18(03):177-191

114 Harish S, Chiavaras MM, Kotnis N, Rebello R. MR imaging of skeletal soft tissue infection: utility of diffusion-weighted imaging in detecting abscess formation. Skeletal Radiol 2011;40(03): 285-294

115 Bluemke DA, Fishman EK, Scott WW Jr. Skeletal complications of radiation therapy. Radiographics 1994;14(01):111-121

116 Moore LF, Kransdorf MJ, Buskirk SJ, O'Connor MI, Menke DM. Radiation-induced pseudotumor following therapy for soft tissue sarcoma. Skeletal Radiol 2009;38(06):579-584

117 O'Connell JX, English JC, Beauchamp CP, Connell DG. Intramuscular hypertrophic scar: an unusual complication following soft tissue sarcoma resection. Skeletal Radiol 1995;24(04): 305-307

118 Radtke C, Vogt PM. Nerve injuries and posttraumatic therapy [in German]. Unfallchirurg 2014;117(06):539-555; quiz 556

119 Wolford LM, Stevao EL. Considerations in nerve repair. Proc Bayl Univ Med Cent 2003;16(02):152-156

120 Kerimoglu U, Canyigit M. Paradoxic hypertrophy of the sciatic nerve in adult patients after above-knee amputation. Acta Radiol 2007;48(09):1028-1031

121 Grieser T, Nöbauer-Huhmann IM. Postoperative and posttherapeutic changes after primary bone tumors : what's important for radiologists? [in German]. Radiologe 2017;57(11): 938-957

122 Waters B, Panicek DM, Lefkowitz RA, et al. Low-grade myxofibrosarcoma: CT and MRI patterns in recurrent disease. AJR Am J Roentgenol 2007;188(02):W193-W198
123 Ezuddin NS, Pretell-Mazzini J, Yechieli RL, Kerr DA, Wilky BA, Subhawong TK. Local recurrence of soft-tissue sarcoma: issues in imaging surveillance strategy. Skeletal Radiol 2018;47(12): 1595-1606

124 Alpert JS, Boland P, Hameed M, Panicek DM. Undifferentiated pleomorphic sarcoma: indolent, tail-like recurrence of a highgrade tumor. Skeletal Radiol 2018;47(01):141-144

125 Kotnis NA, Grimer RJ, Davies AM, James SL. Magnetic resonance imaging appearances following hindquarter amputation for pelvic musculoskeletal malignancy. Skeletal Radiol 2009;38 (12):1137-1146

126 Kransdorf MJ, Murphey MD. Soft tissue tumors: post-treatment imaging. Radiol Clin North Am 2006;44(03):463-472

127 Panicek DM, Schwartz LH, Heelan RT, Caravelli JF. Non-neoplastic causes of high signal intensity at T2-weighted MR imaging after treatment for musculoskeletal neoplasm. Skeletal Radiol 1995; 24(03):185-190

128 Shapeero LG, Vanel D, Verstraete KL, Bloem JL. Fast magnetic resonance imaging with contrast for soft tissue sarcoma viability. Clin Orthop Relat Res 2002;(397):212-227

129 Baur A, Huber A, Arbogast S, et al. Diffusion-weighted imaging of tumor recurrencies and posttherapeutical soft-tissue changes in humans. Eur Radiol 2001;11(05):828-833

130 Murphey MD, Arcara LK, Fanburg-Smith J. From the archives of the AFIP: imaging of musculoskeletal liposarcoma with radiologic-pathologic correlation. Radiographics 2005;25(05):13711395

131 Tateishi U, Hasegawa T, Beppu Y, Satake M, Moriyama N. Primary dedifferentiated liposarcoma of the retroperitoneum. Prognostic significance of computed tomography and magnetic resonance imaging features. J Comput Assist Tomogr 2003;27 (05):799-804

132 Patel SR. Radiation-induced sarcoma. Curr Treat Options Oncol 2000;1(03):258-261

133 Lagrange JL, Ramaioli A, Chateau MC, et al; Radiation Therapist and Pathologist Groups of the Fédération Nationale des Centres de Lutte Contre le Cancer. Sarcoma after radiation therapy: retrospective multiinstitutional study of 80 histologically confirmed cases. Radiology 2000;216(01):197-205

134 Sheppard DG, Libshitz HI. Post-radiation sarcomas: a review of the clinical and imaging features in 63 cases. Clin Radiol 2001;56 (01):22-29

135 Kim JH, Chu FC, Woodard HQ Melamed MR, Huvos A, Cantin J. Radiation-induced soft-tissue and bone sarcoma. Radiology 1978;129(02):501-508

136 Laskin WB, Silverman TA, Enzinger FM. Postradiation soft tissue sarcomas. An analysis of 53 cases. Cancer 1988;62(11):2330-2340

Erratum: This article has been corrected in accordance with the Erratum published on January 7, 2021. Figures $1 \mathrm{a}-\mathrm{b}$ and $2 \mathrm{a}-\mathrm{b}$ have been corrected. 